Portland State University

PDXScholar

\title{
The Boulevard Study: From Arterial to Asset -- Examining the Role of the Multi-Way Boulevard in Coordinated Transportation and Land Use Planning
}

Mark L. Gillem

University of Oregon

Follow this and additional works at: https://pdxscholar.library.pdx.edu/trec_reports

Part of the Transportation Commons, Urban Studies Commons, and the Urban Studies and Planning Commons

Let us know how access to this document benefits you.

Recommended Citation

Gillem, Mark. The Boulevard Study: From Arterial to Asset -- Examining the Role of the Multi-Way Boulevard in Coordinated Transportation and Land Use Planning. OTREC-RR-10-10. Portland, OR: Transportation Research and Education Center (TREC), 2010. https://doi.org/10.15760/trec.85

This Report is brought to you for free and open access. It has been accepted for inclusion in TREC Final Reports by an authorized administrator of PDXScholar. Please contact us if we can make this document more accessible: pdxscholar@pdx.edu. 


\section{S)OTREC}

TRANSPORTAMION

\section{The BOULEVARD STUDY From Arterial to Asset - Examining the Role of the Multiway Boulevard in Coordinated Transportation and Land Use Planning}

OTREC-RR-10-10

August 2010 



\title{
THE BOULEVARD STUDY \\ From Arterial to Asset - Examining the Role of the Multiway Boulevard in Coordinated Transportation and Land Use Planning
}

\author{
Final Report \\ OTREC-RR-10-10 \\ by \\ Mark L. Gillem, PhD, AIA, AICP \\ University of Oregon \\ for \\ Oregon Transportation Research \\ and Education Consortium (OTREC) \\ P.O. Box 751 \\ Portland, OR 97207



August 2010 



\section{Technical Report Documentation Page}

\begin{tabular}{|c|c|c|}
\hline $\begin{array}{l}\text { 1. Report No. } \\
\text { OTREC-RR-10-10 }\end{array}$ & 2. Government Accession No. & 3. Recipient's Catalog No. \\
\hline \multirow{2}{*}{\multicolumn{2}{|c|}{$\begin{array}{l}\text { 4. Title and Subtitle } \\
\text { The Boulevard Study: } \\
\text { From Arterial to Asset -- Examining the Role of the Multi-Way Boulevard in Coordinated } \\
\text { Transportation and Land Use Planning: Final Report }\end{array}$}} & $\begin{array}{l}\text { 5. Report Date } \\
\text { August } 2010\end{array}$ \\
\hline & & 6. Performing Organization Code \\
\hline \multicolumn{2}{|l|}{ 7. Author(s) } & $\begin{array}{l}\text { 8. Performing Organization Report No. } \\
\text { University of Oregon }\end{array}$ \\
\hline \multirow{2}{*}{\multicolumn{2}{|c|}{$\begin{array}{l}\text { 9. Performing Organization Name and Address } \\
\text { University of Oregon } \\
\text { School of Architecture and Allied Arts } \\
\text { Department of Architecture } \\
\text { Eugene, OR 97403-1206 }\end{array}$}} & 10. Work Unit No. (TRAIS) \\
\hline & & $\begin{array}{l}\text { 11. Contract or Grant No. } \\
2007-1\end{array}$ \\
\hline \multirow{2}{*}{\multicolumn{2}{|c|}{$\begin{array}{l}\text { 12. Sponsoring Agency Name and Address } \\
\text { Oregon Transportation Research } \\
\text { and Education Consortium (OTREC) } \\
\text { P.O. Box } 751 \\
\text { Portland, Oregon } 97207\end{array}$}} & $\begin{array}{l}\text { 13. Type of Report and Period Covered } \\
\text { Final Report }\end{array}$ \\
\hline & & 14. Sponsoring Agency Code \\
\hline
\end{tabular}

15. Supplementary Notes

\section{Abstract}

As citizens of the Eugene-Springfield metropolitan area consider options for meeting the residential needs of the next generation, they need look no further than their own transportation corridors. Arterials like West 11th, Franklin Boulevard, and East Main Street can be converted into multiway boulevards that can act as magnets for new residential and commercial development in the core of town. These boulevards can accommodate through and local traffic, public transit, pedestrians, and infill residential and mixed-use development. However, given the current configuration of these arterials, residential developers rightly ignore these parts of town and opt to build at the edge of town. These existing arterials are eyesores with low-density auto-oriented strip development. Given the right public investment, private development will be attracted once again to these corridors, which can relieve pressure on the existing Urban Growth Boundary and reduce development on prime farmland or other sensitive lands. To identify the capacity and potential of West 11 th, Franklin Boulevard, and East Main Street, research based design studios at the University of Oregon conducted an applied research project that examined the opportunities and constraints to converting auto-oriented fiveand six-lane arterials into multiway boulevards with transit as a way of reducing congestion, improving pedestrian and automobile safety, and supporting more unified land uses. The study is well aligned with the Oregon Transportation Research and Education Consortium's theme of integrating land use and transportation planning as well as U.S. Department of Transportation (USDOT) strategic objectives focused on improving safety, enhancing mobility, and minimizing transportation related environmental impacts.

17. Key Words

multi-way boulevards, environmental forecasting, vehicle miles travelled, 8. Distribution Statement

carbon reductions, farmland preservation, infill development No restrictions. Copies available from OTREC: www.otrec.us

\begin{tabular}{l|l|l|l}
\hline $\begin{array}{l}\text { 19. Security Classification (of this report) } \\
\text { Unclassified }\end{array}$ & $\begin{array}{l}\text { 20. Security Classification (of this page) } \\
\text { Unclassified }\end{array}$ & $\begin{array}{l}\text { 21. No. of Pages } \\
50\end{array}$
\end{tabular}





\section{ACKNOWLEDGEMENTS}

This study was made possible by generous grants from the Oregon Transportation research and Education Consortium (OTREC).

\section{DISCLAIMER}

The contents of this report reflect the views of the authors, who are solely responsible for the facts and the accuracy of the material and information presented herein. This document is disseminated under the sponsorship of the U.S. Department of Transportation University Transportation Centers Program and the University of Oregon in the interest of information exchange. The U.S. Government and the University of Oregon assumes no liability for the contents or use thereof. The contents do not necessarily reflect the official views of the U.S. Government or the University of Oregon. This report does not constitute a standard, specification, or regulation. 



\section{The Boulevard Study}

Retrofitting Franklin Boulevard, West 11th, and East Main Street in the Eugene/Springfield Metropolitan Area

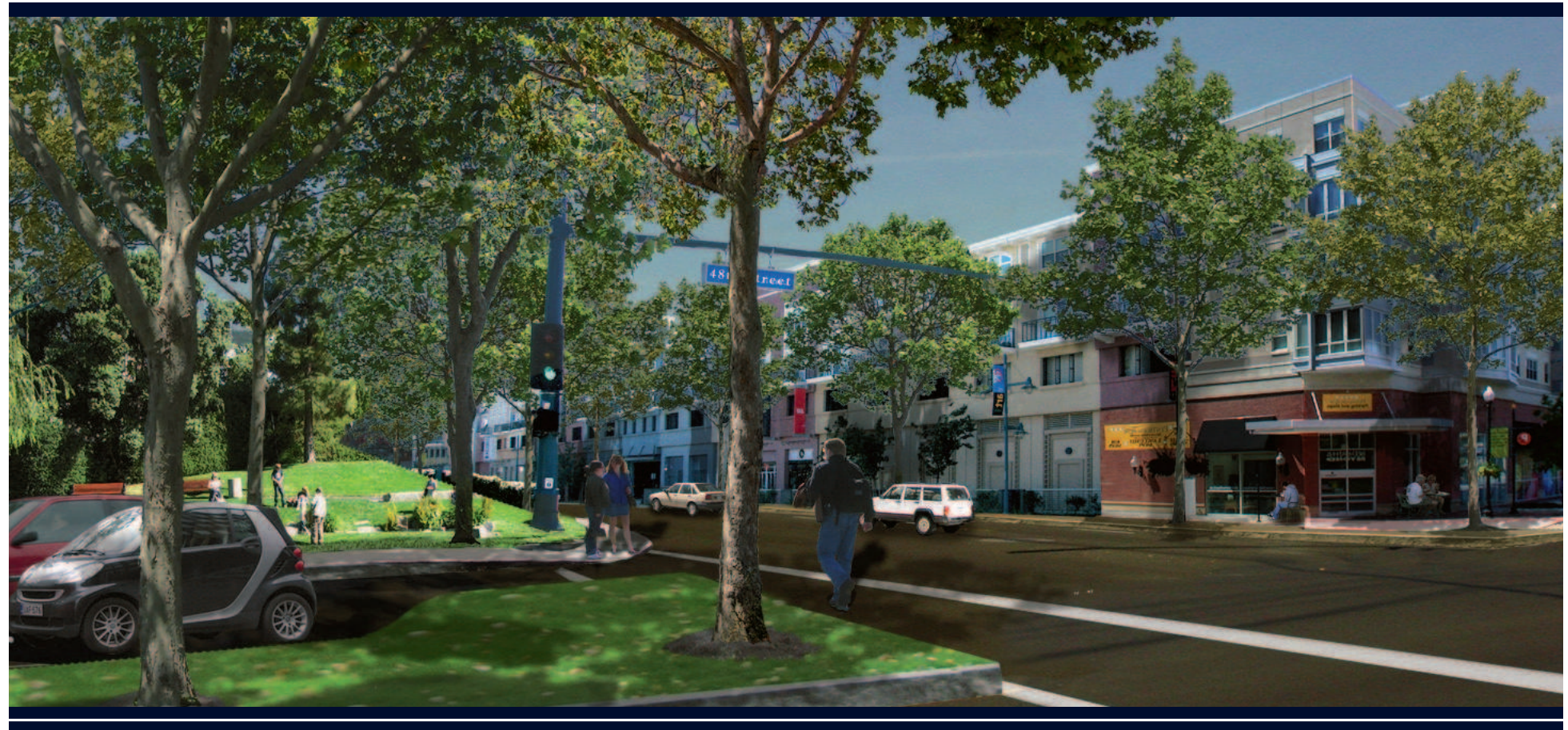

\footnotetext{
University of Oregon

Department of Architecture and Landscape Architecture 2007-2009
}

Mark L. Gillem, PhD, AIA, AICP

Editor 


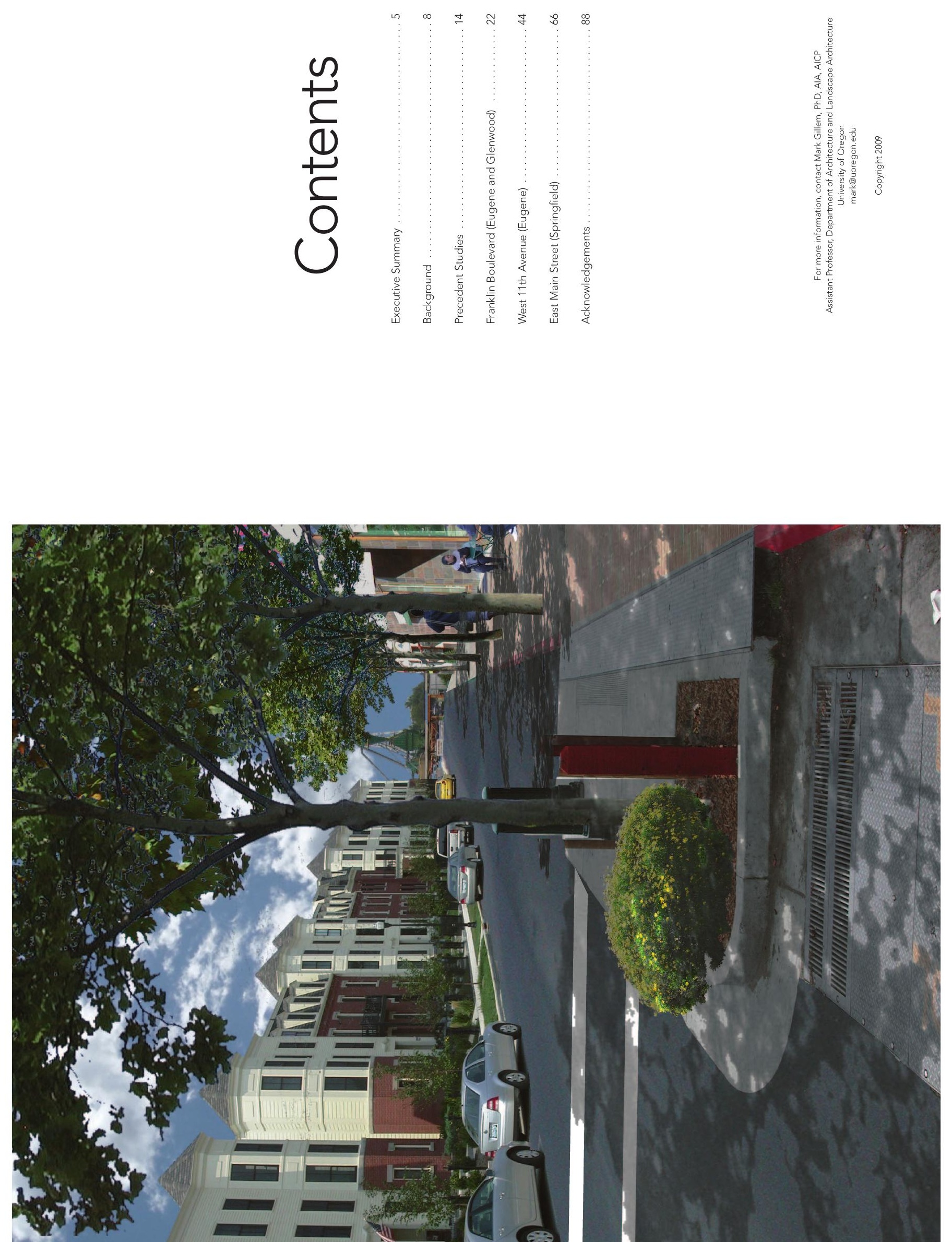

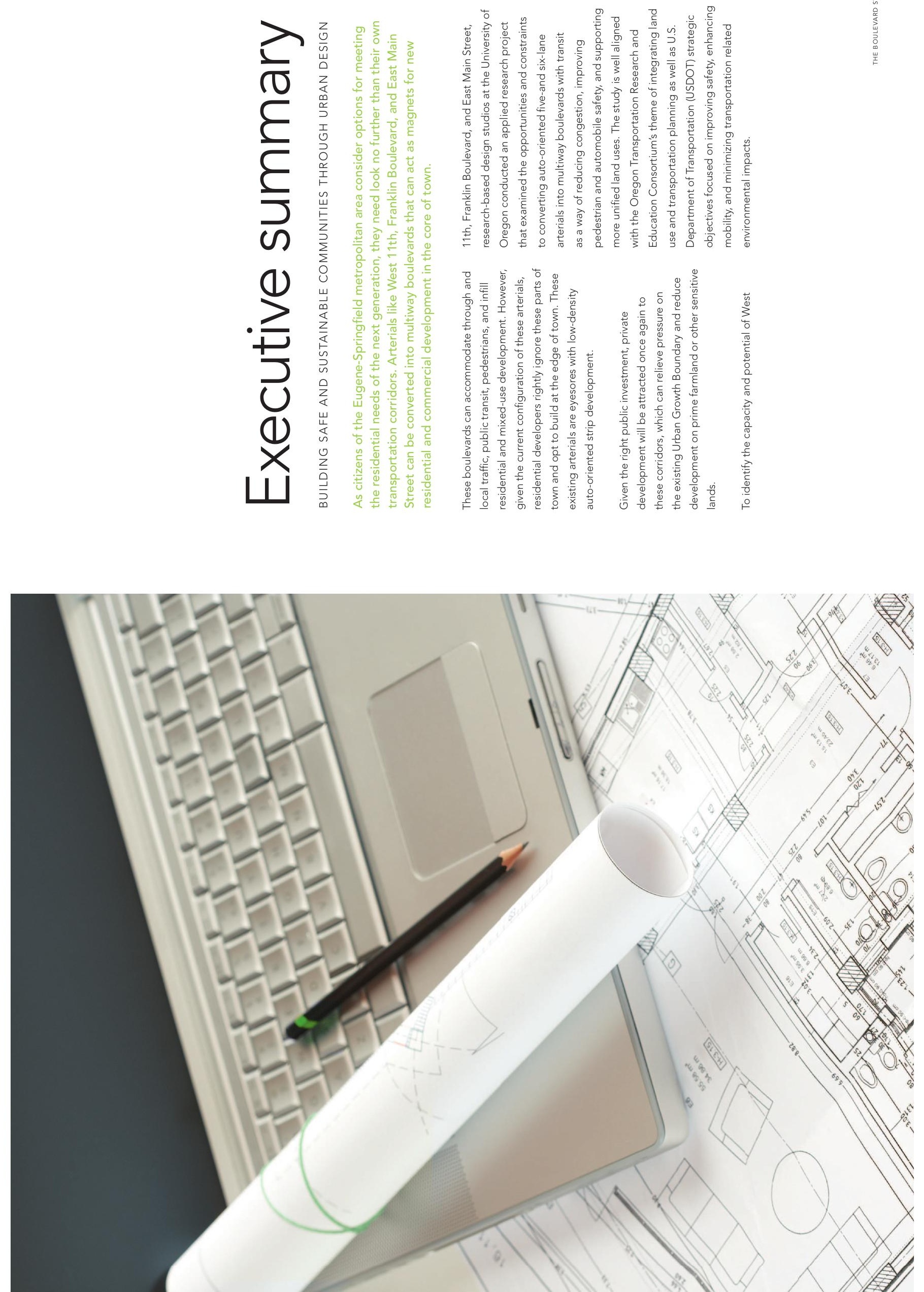


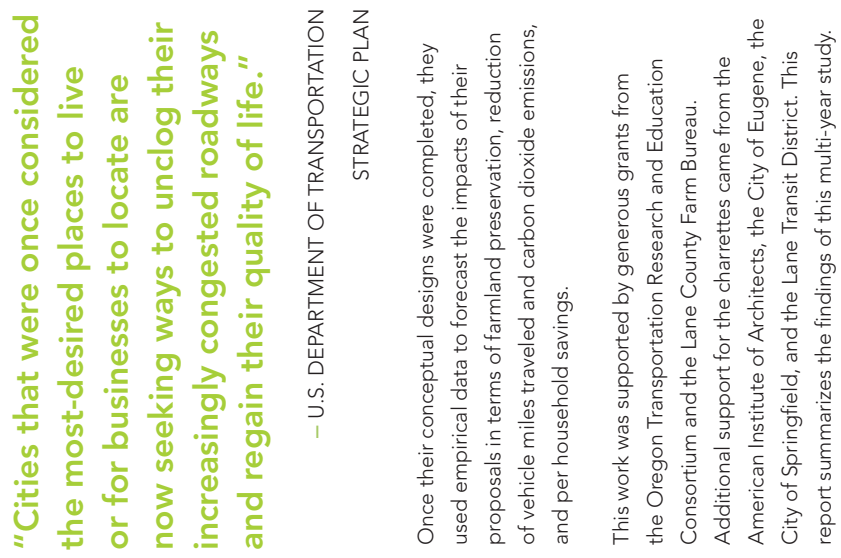

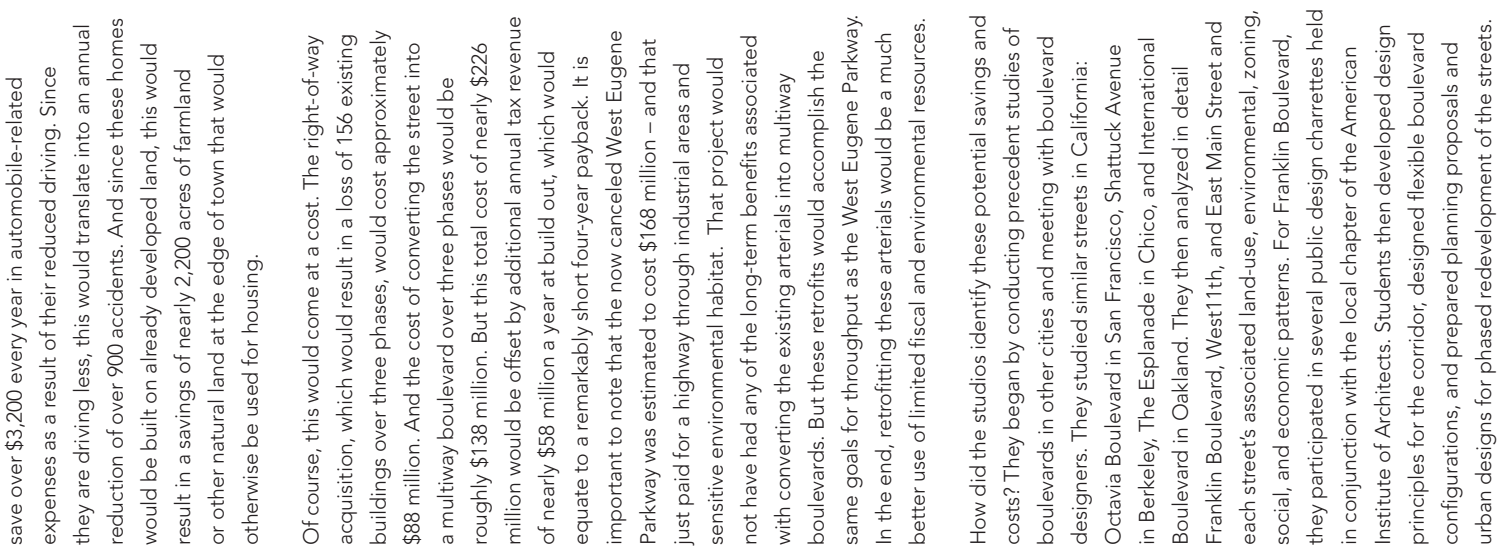

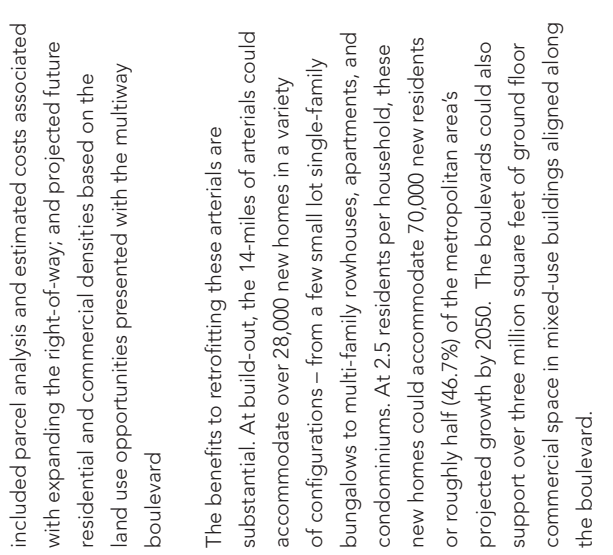

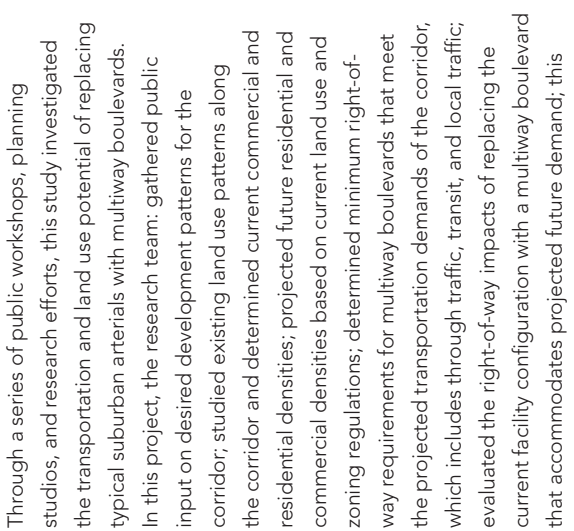
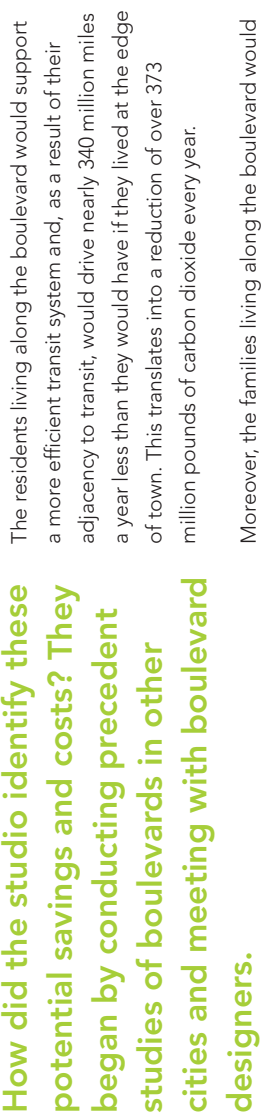

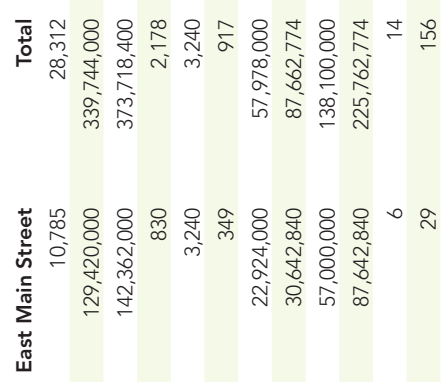

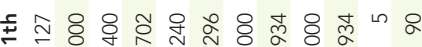

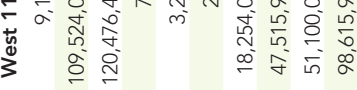

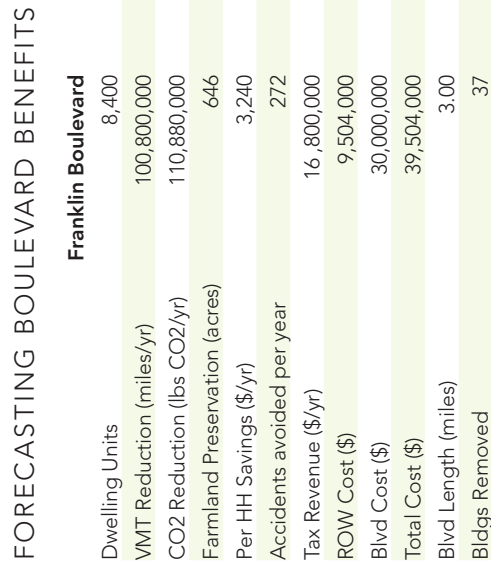



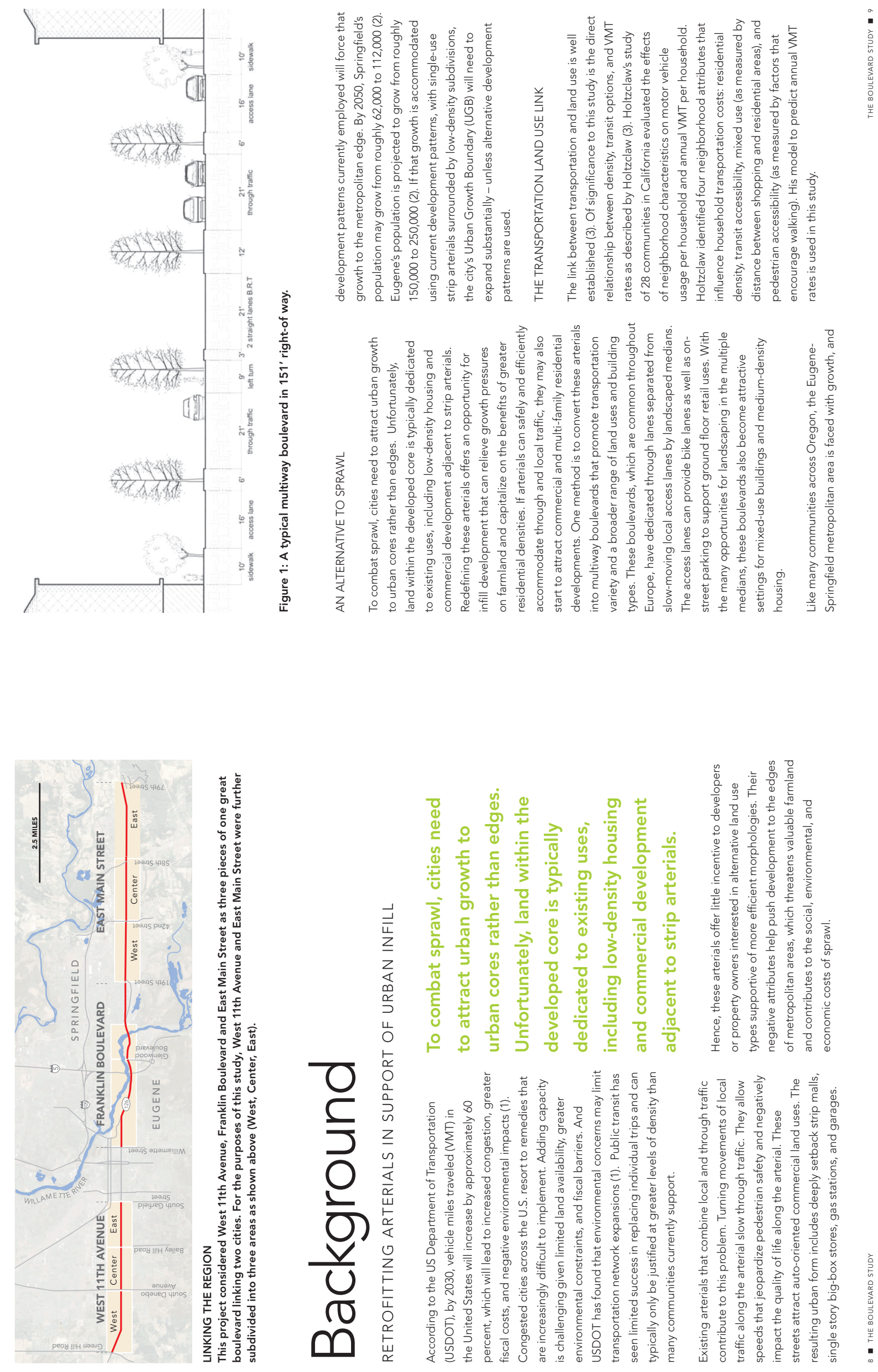

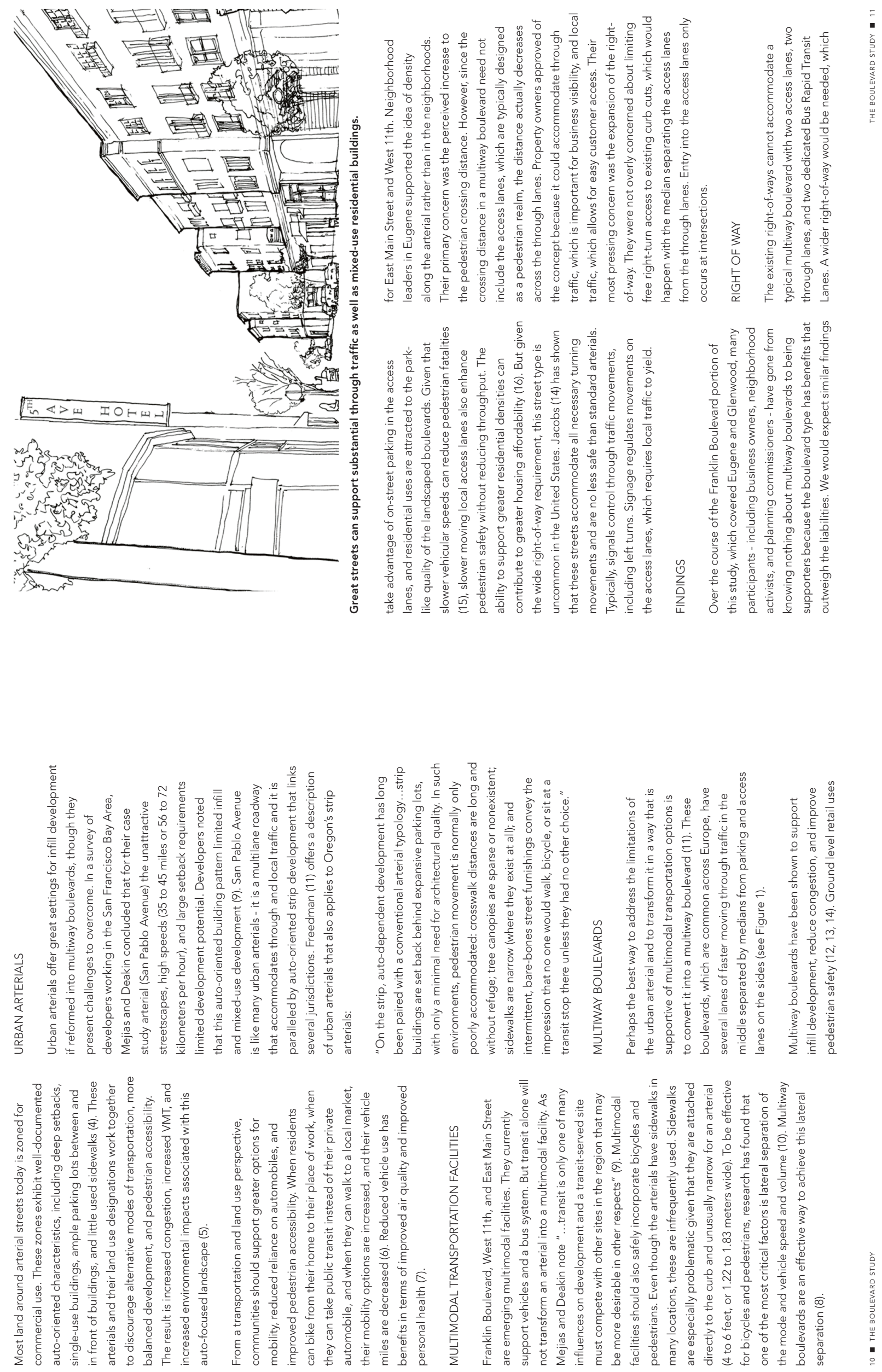

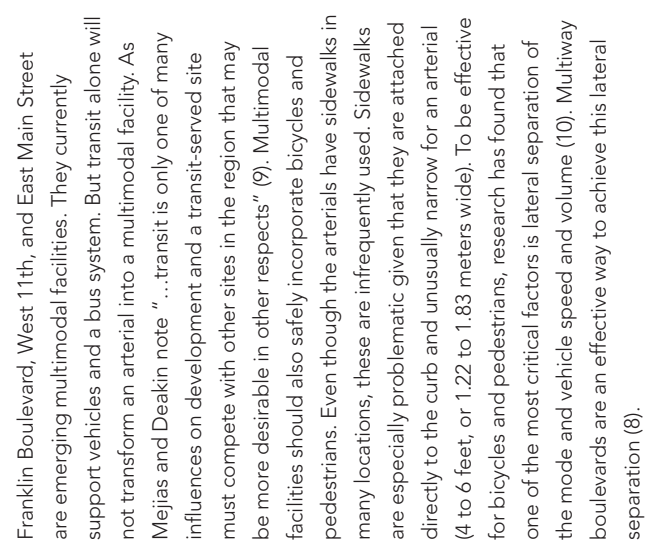




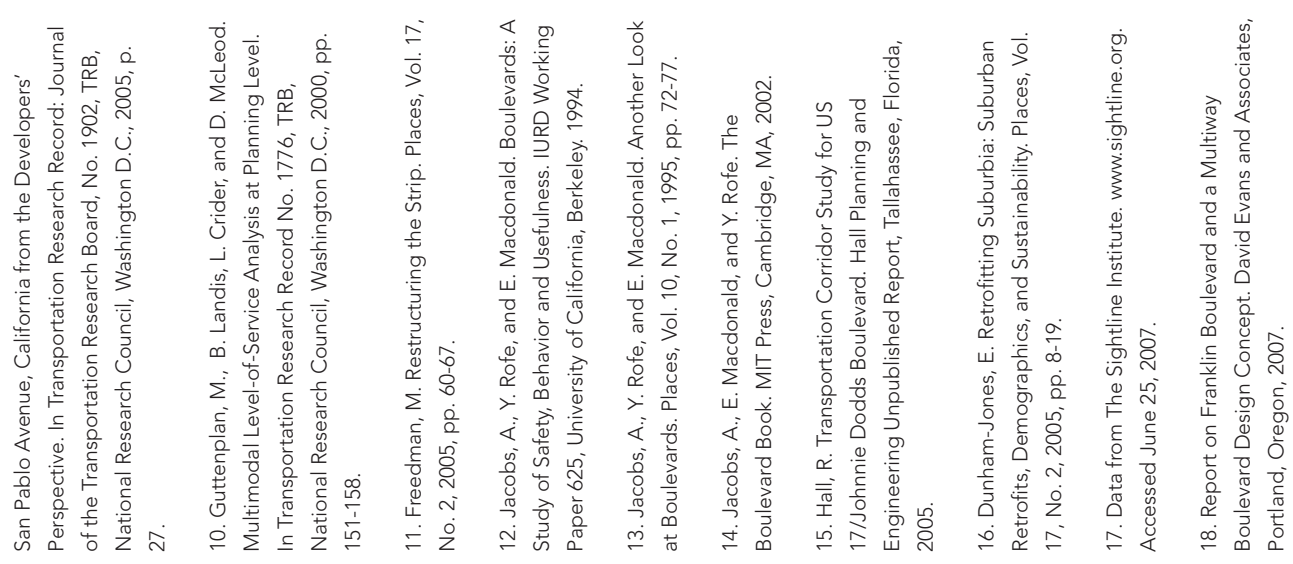

Mn

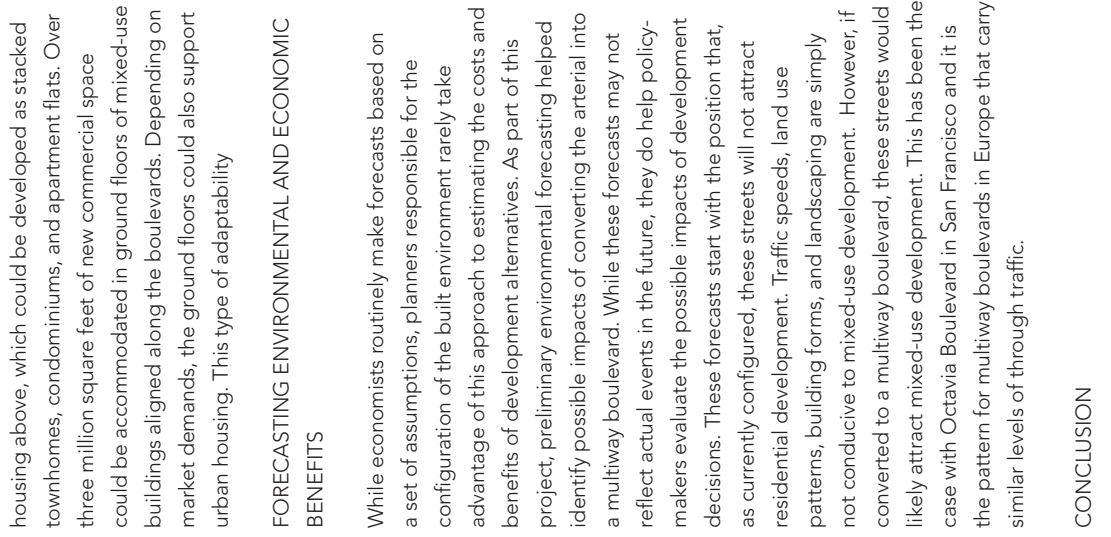

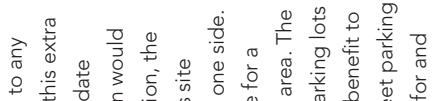

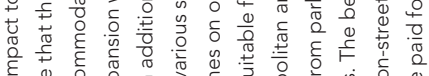

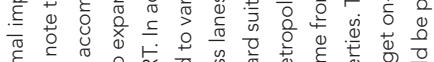

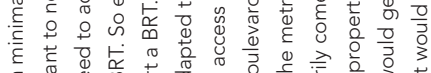

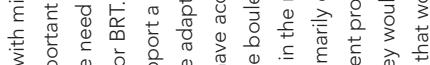

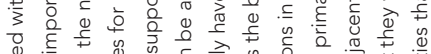

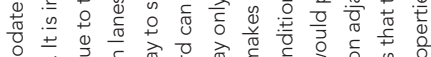

है

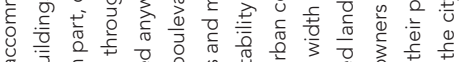

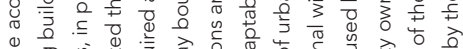

$\begin{array}{llll} & \\ 0 & \\ 0\end{array}$

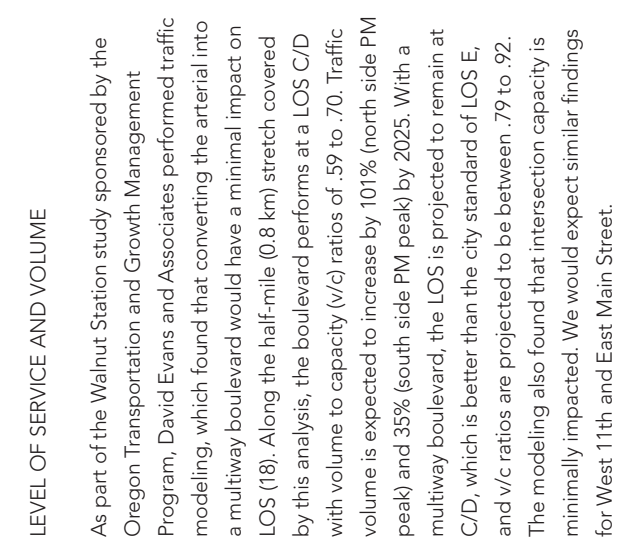




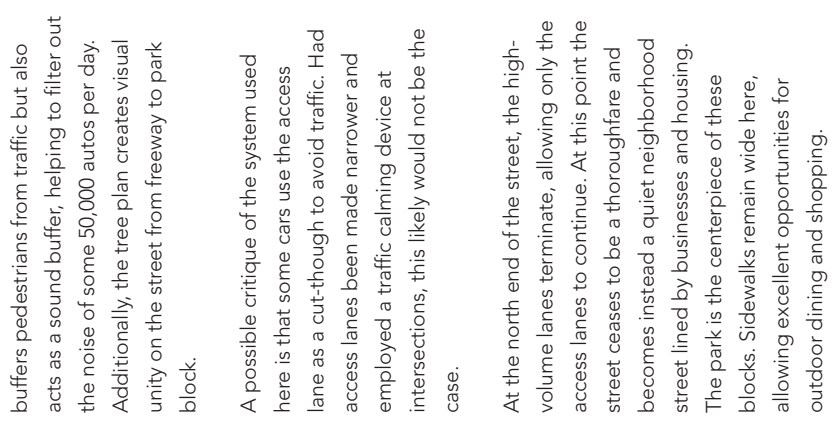
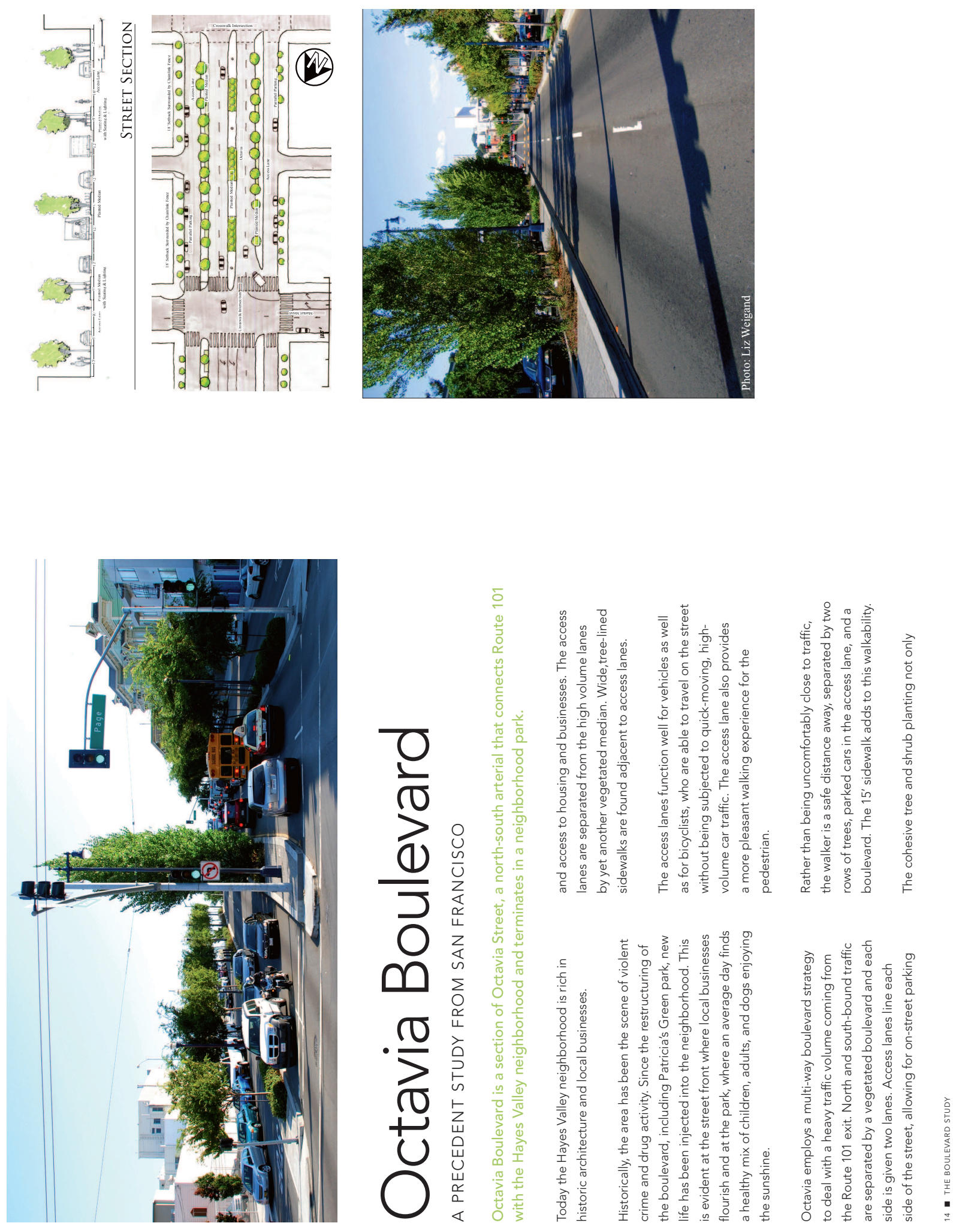

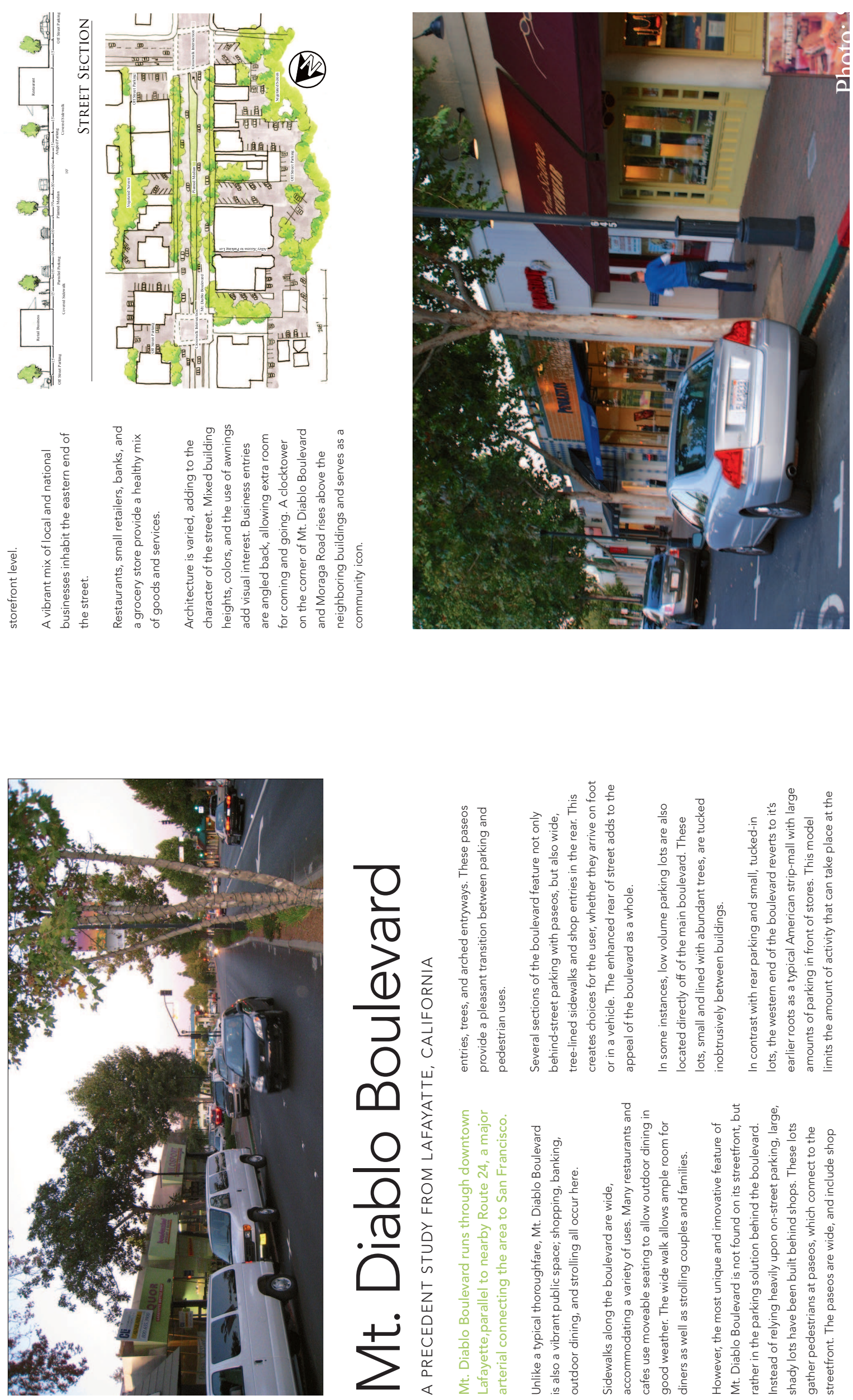

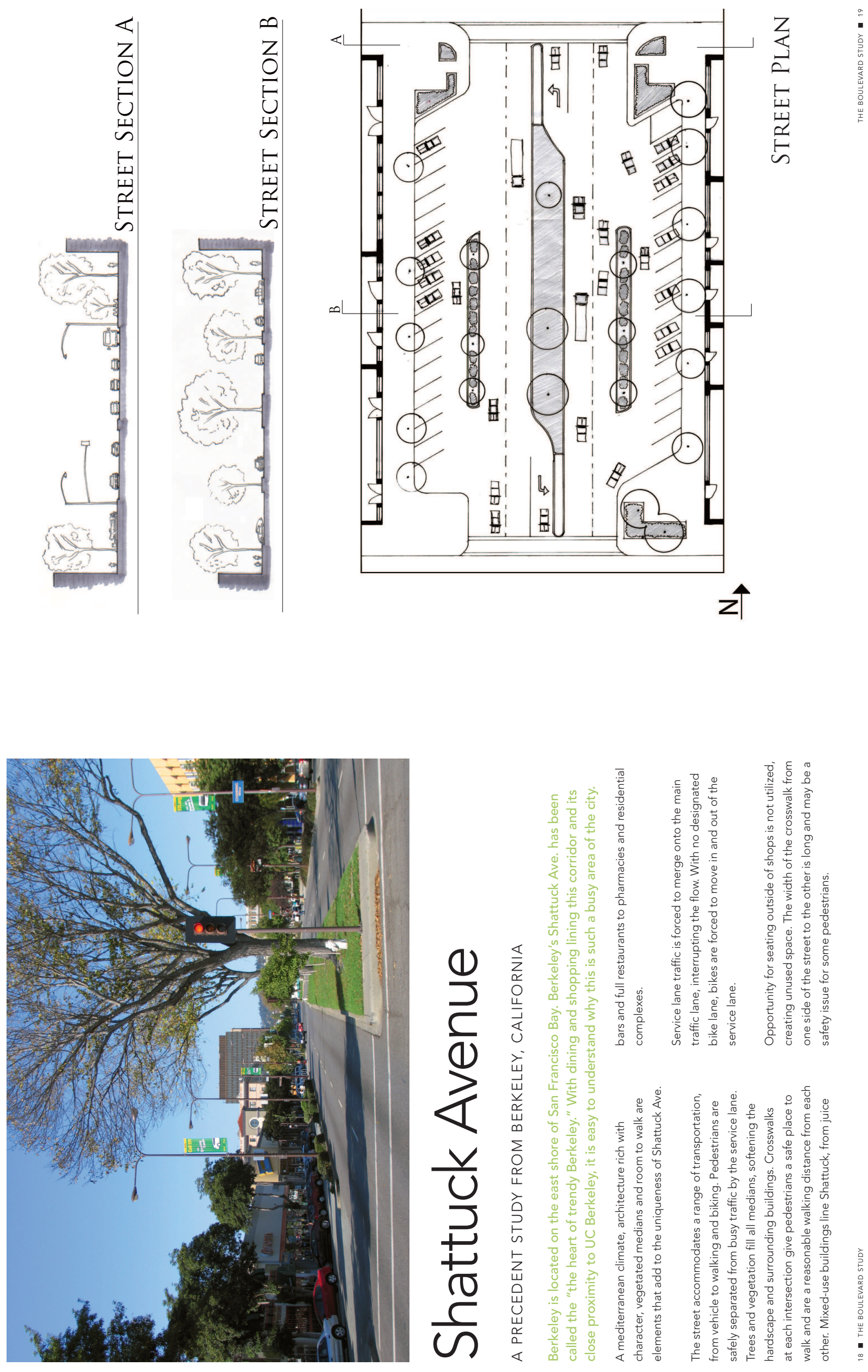

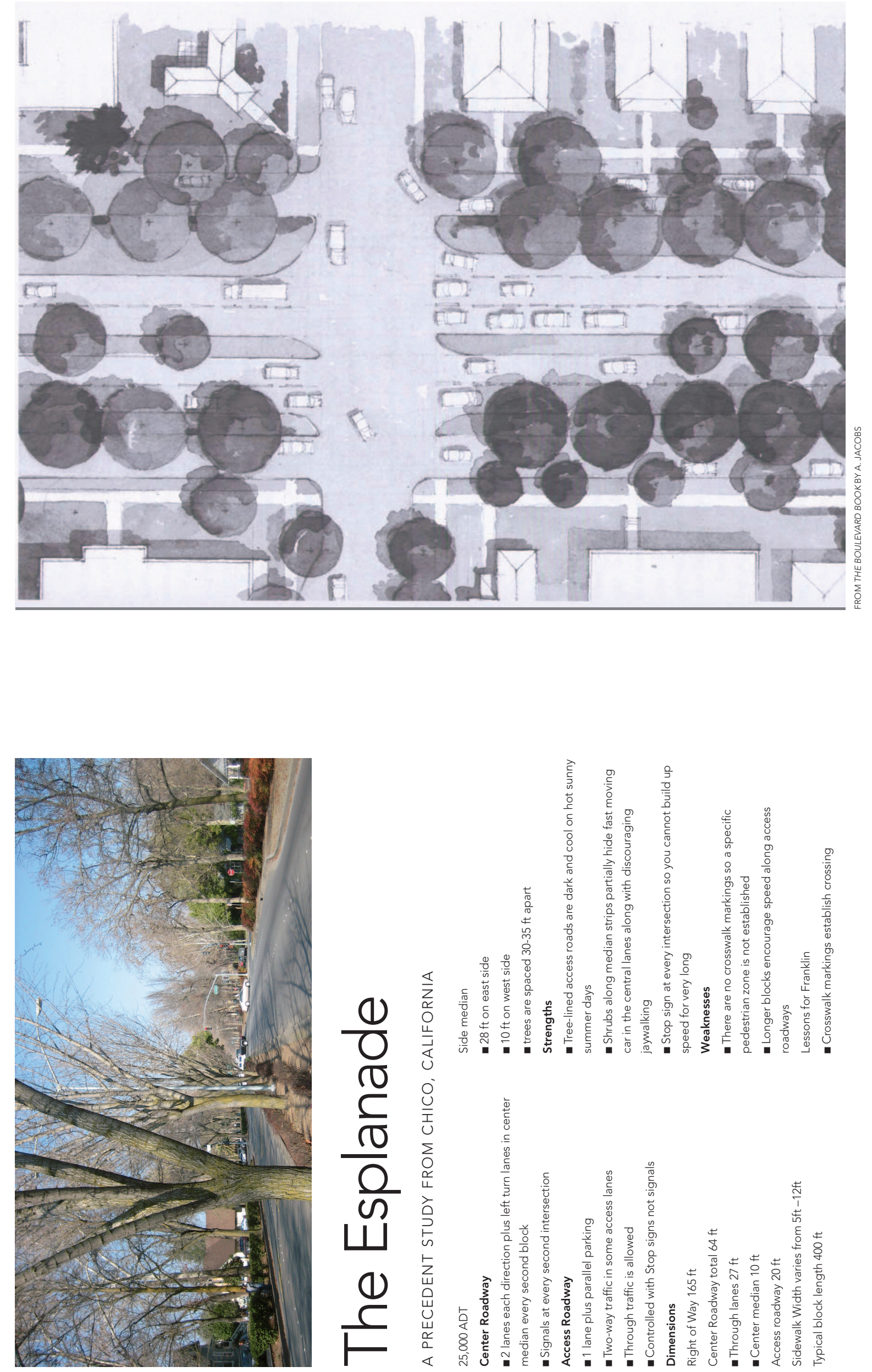


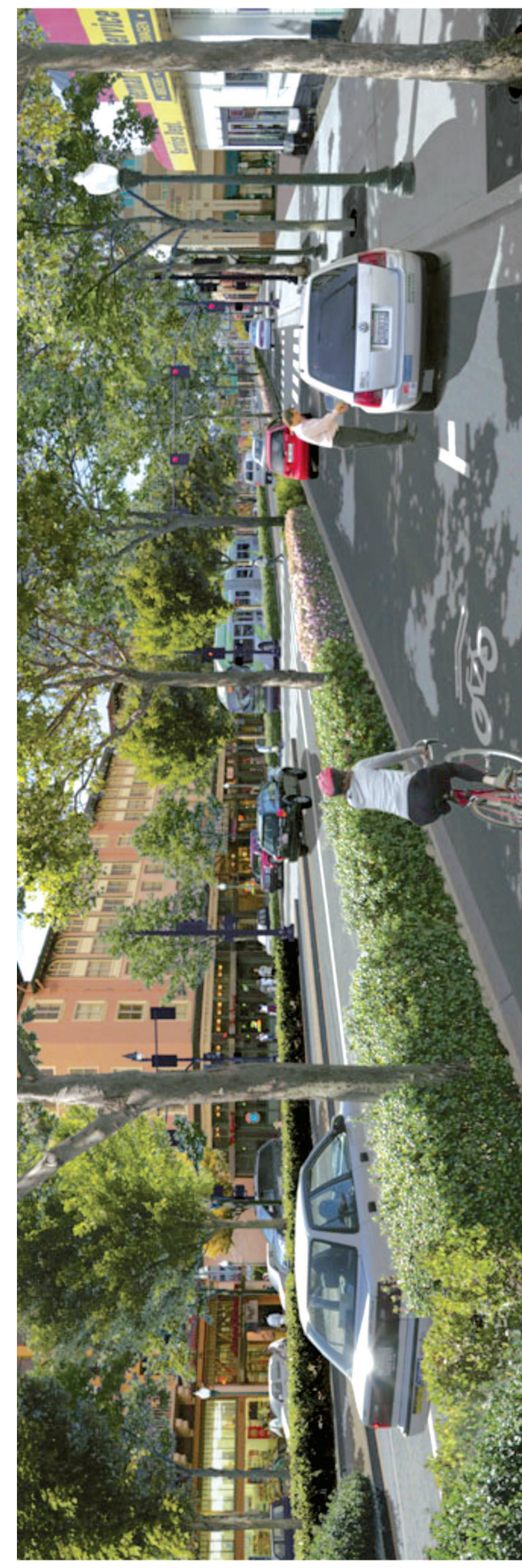

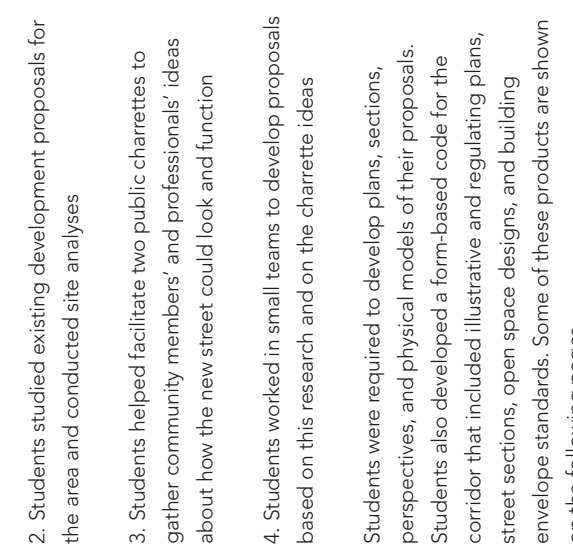
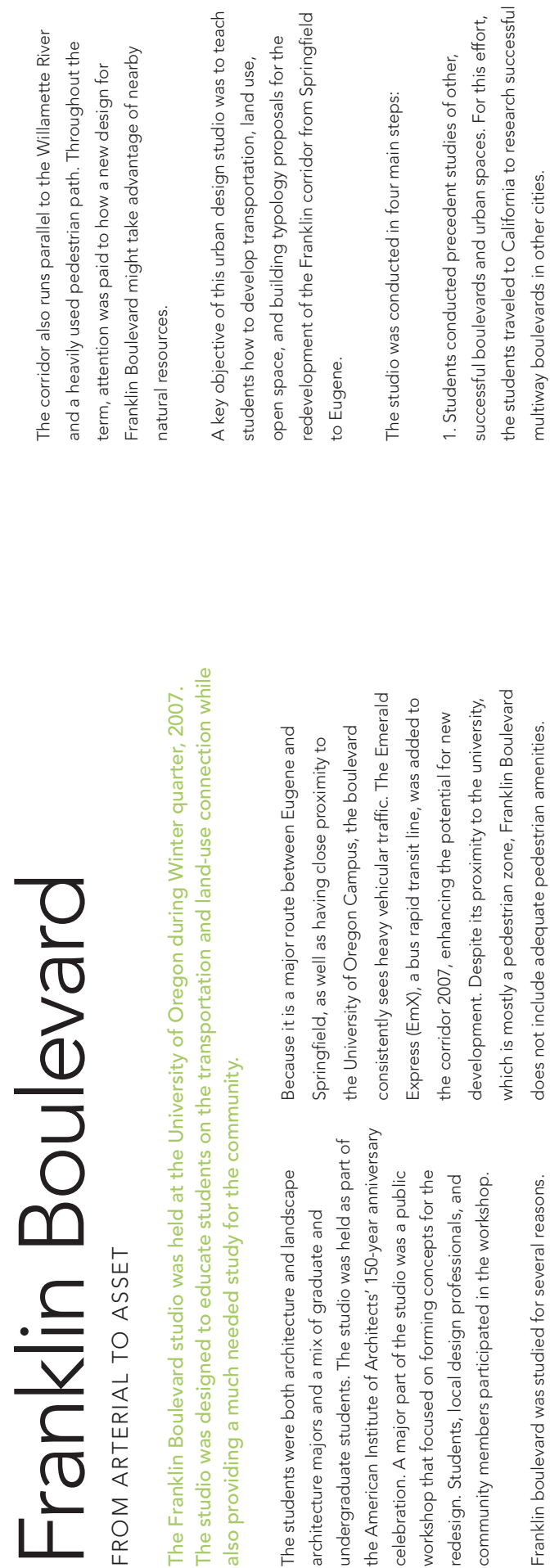

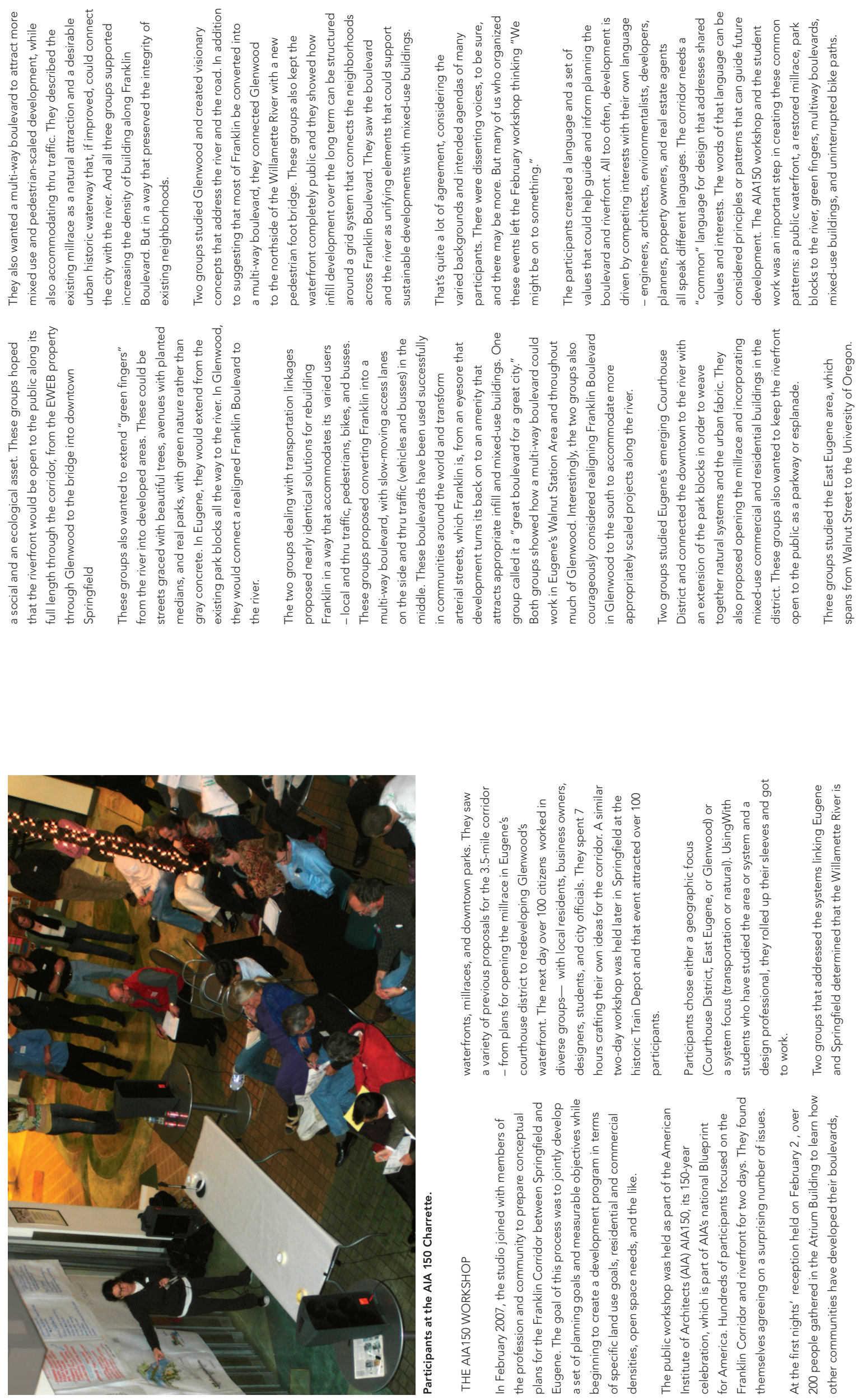

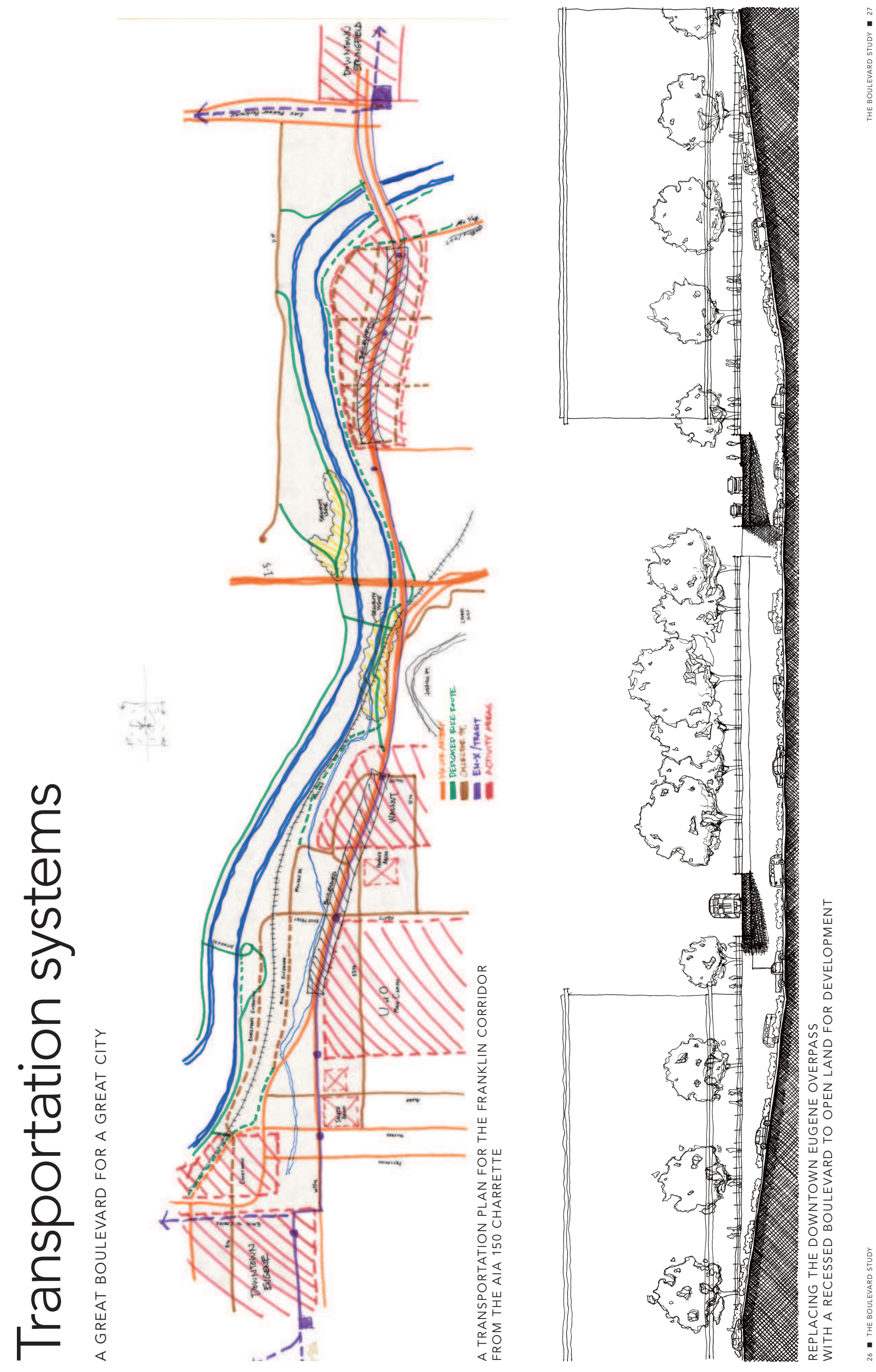

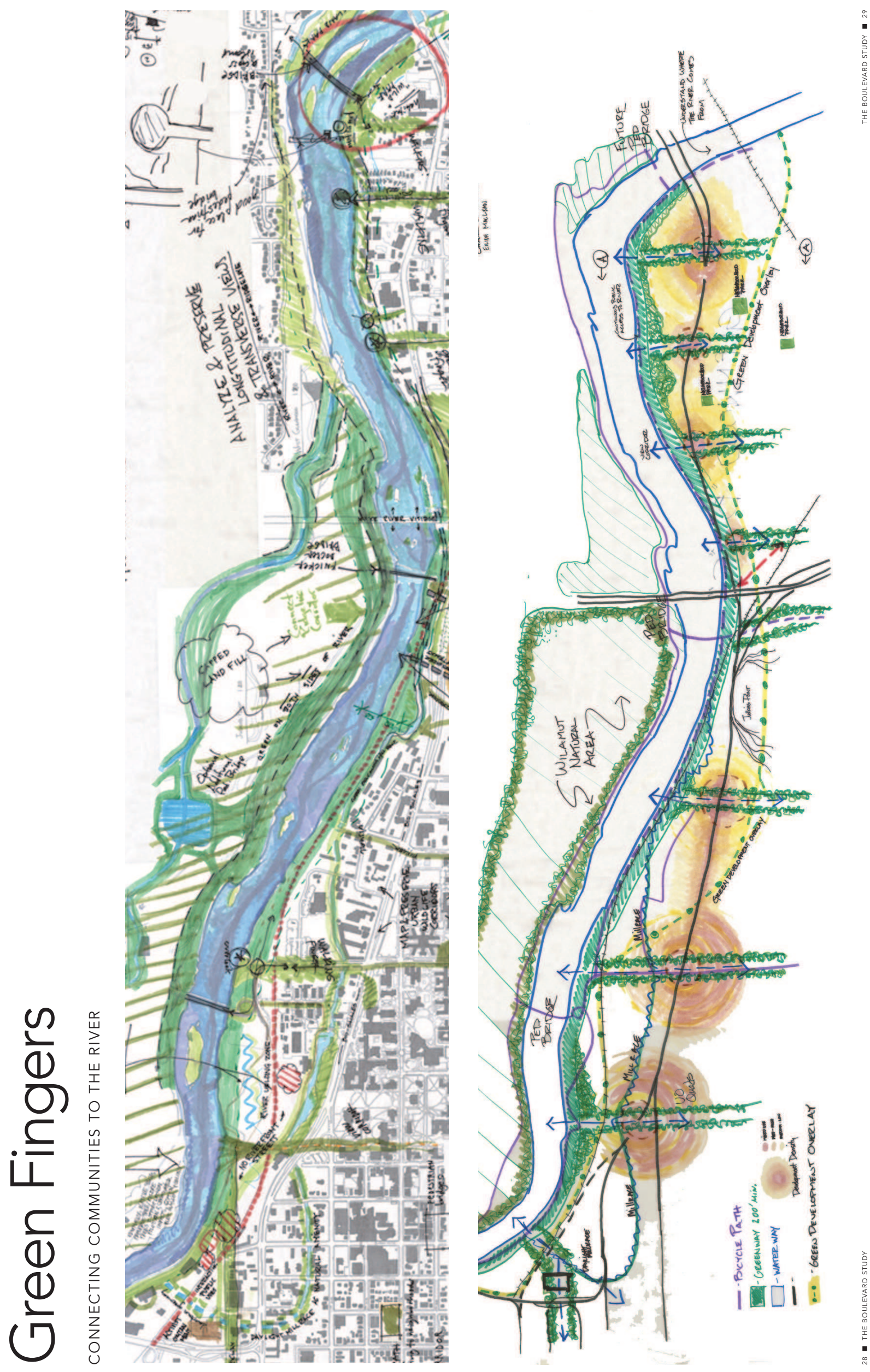

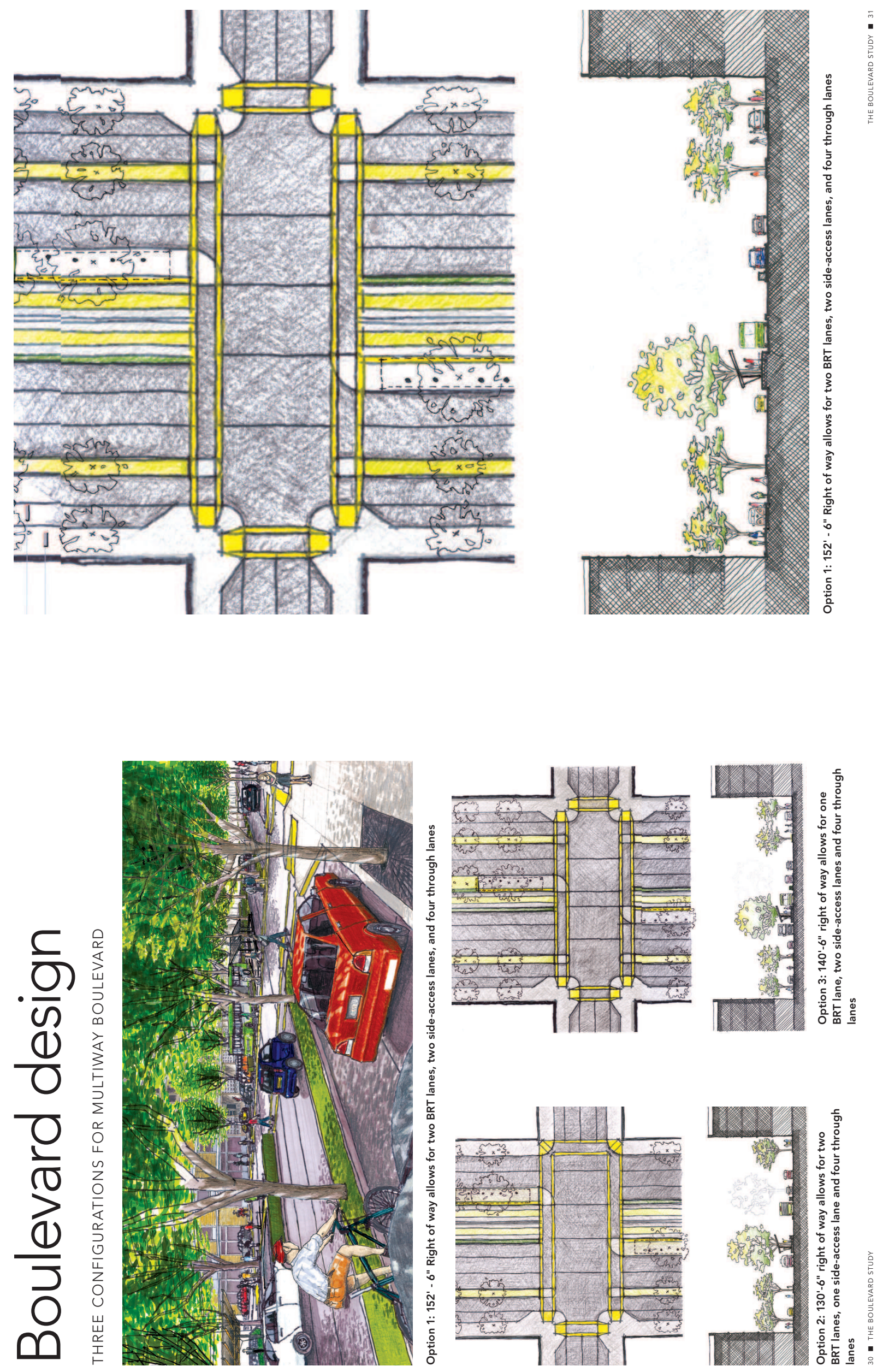

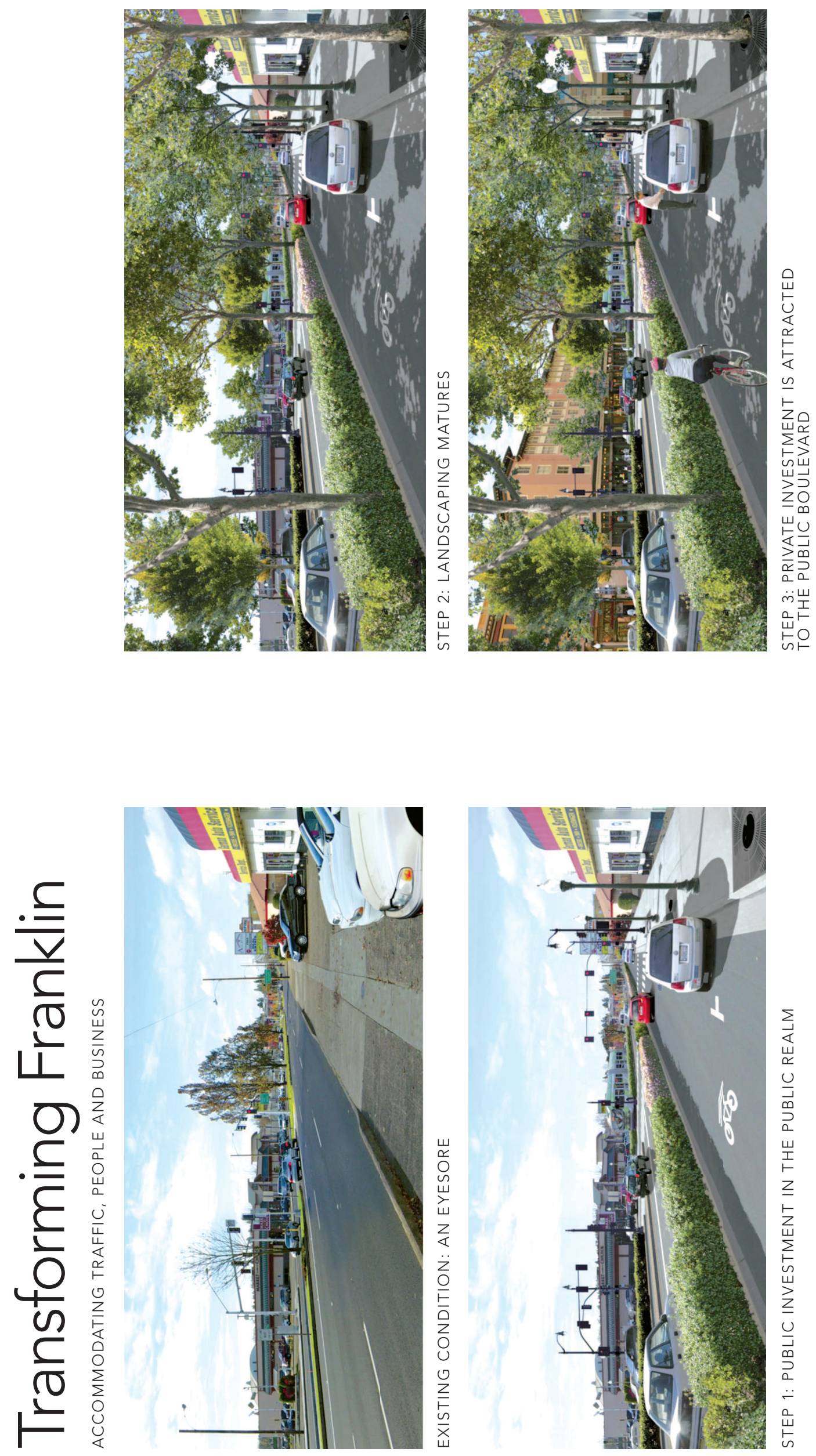

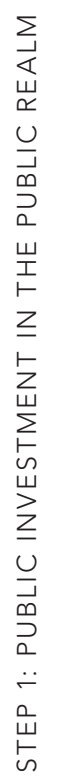



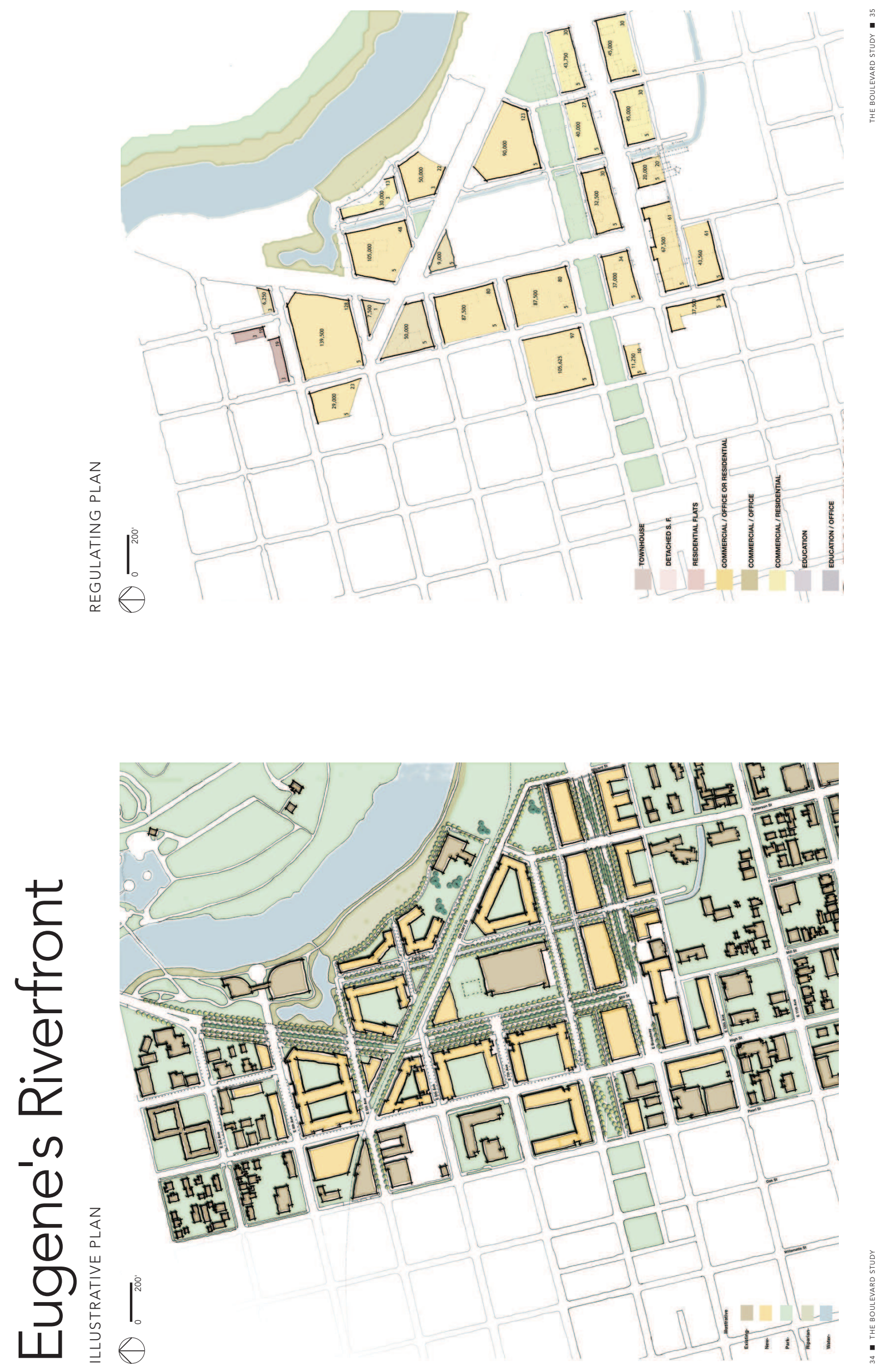

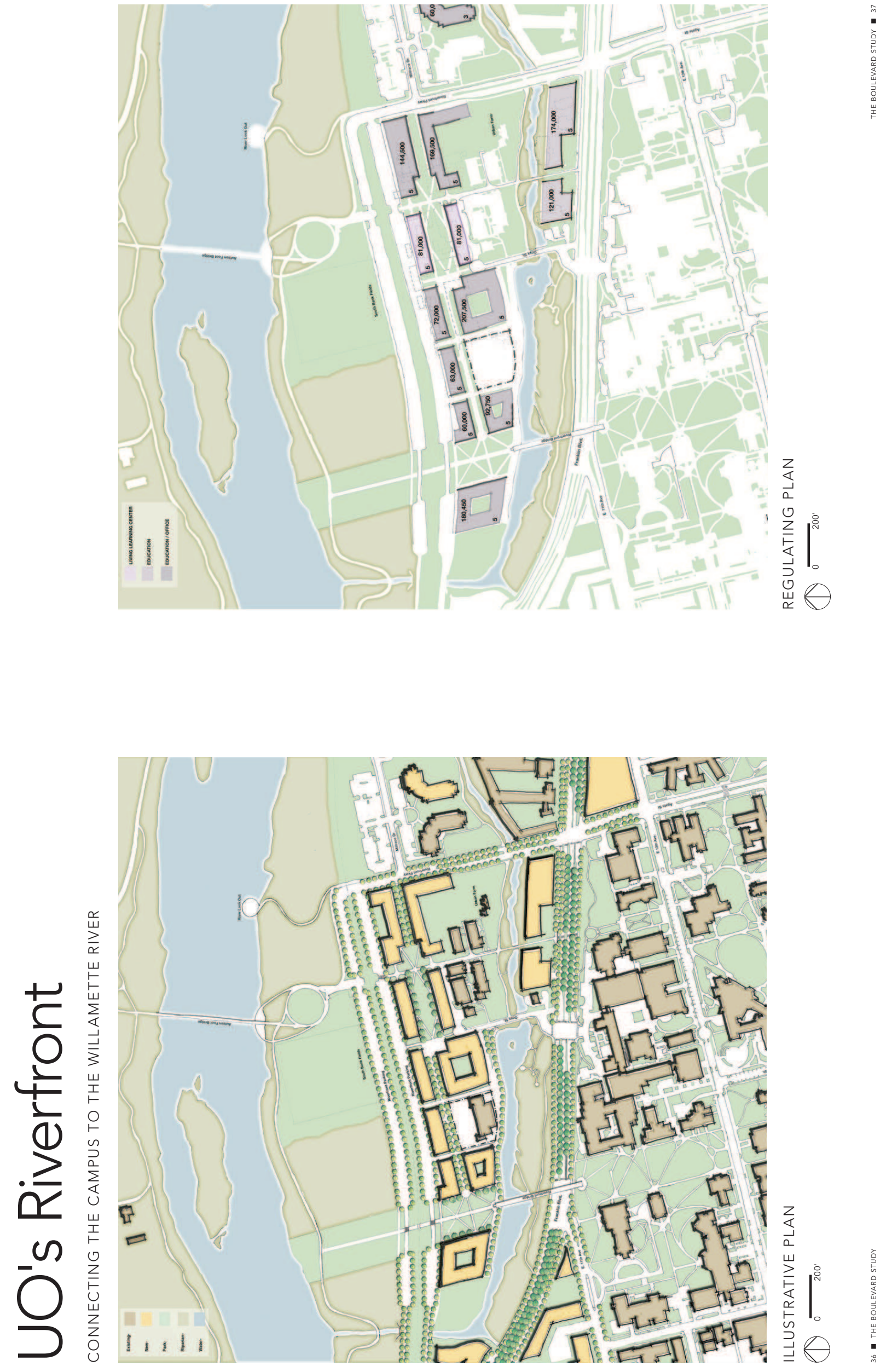

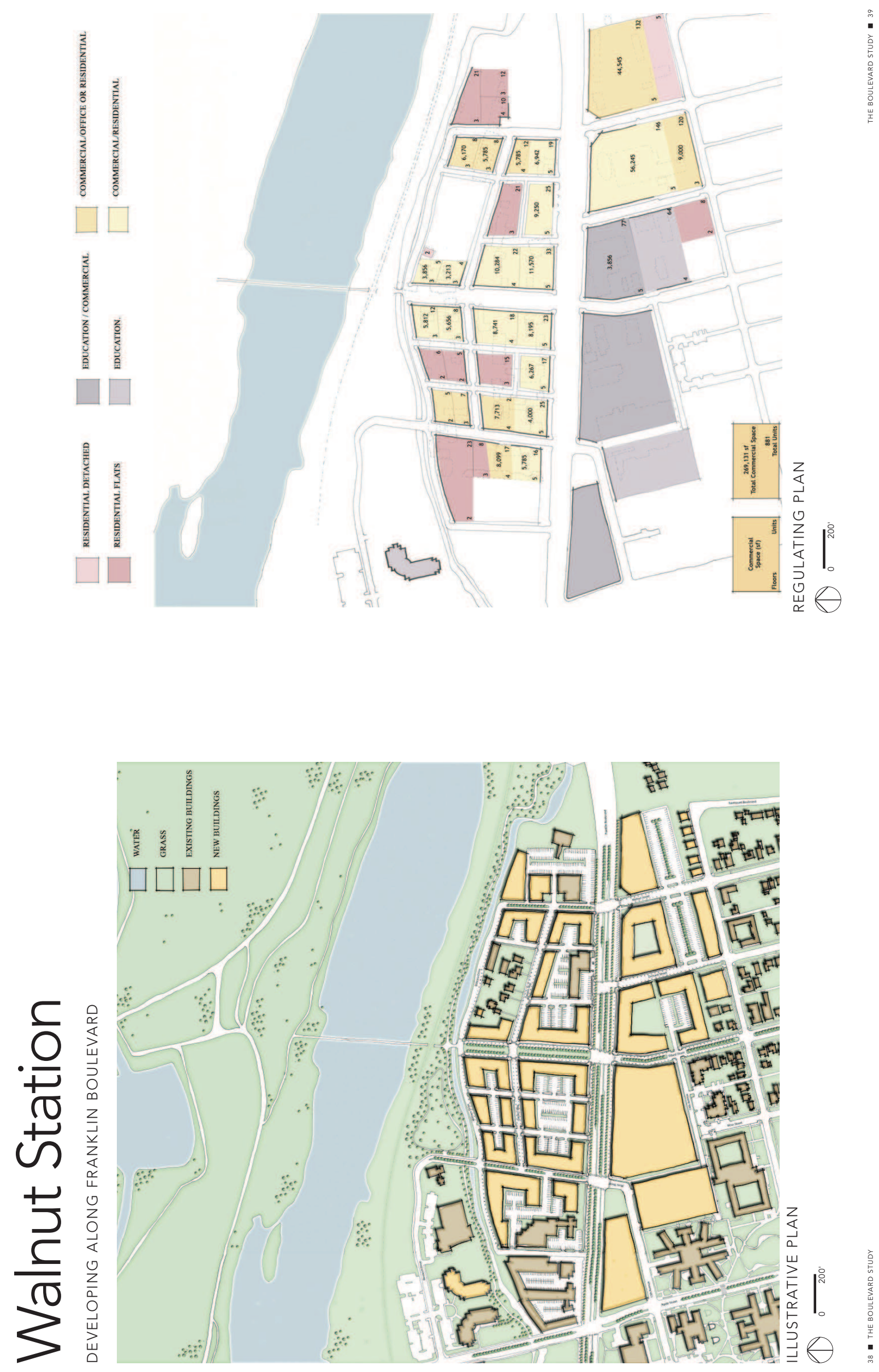


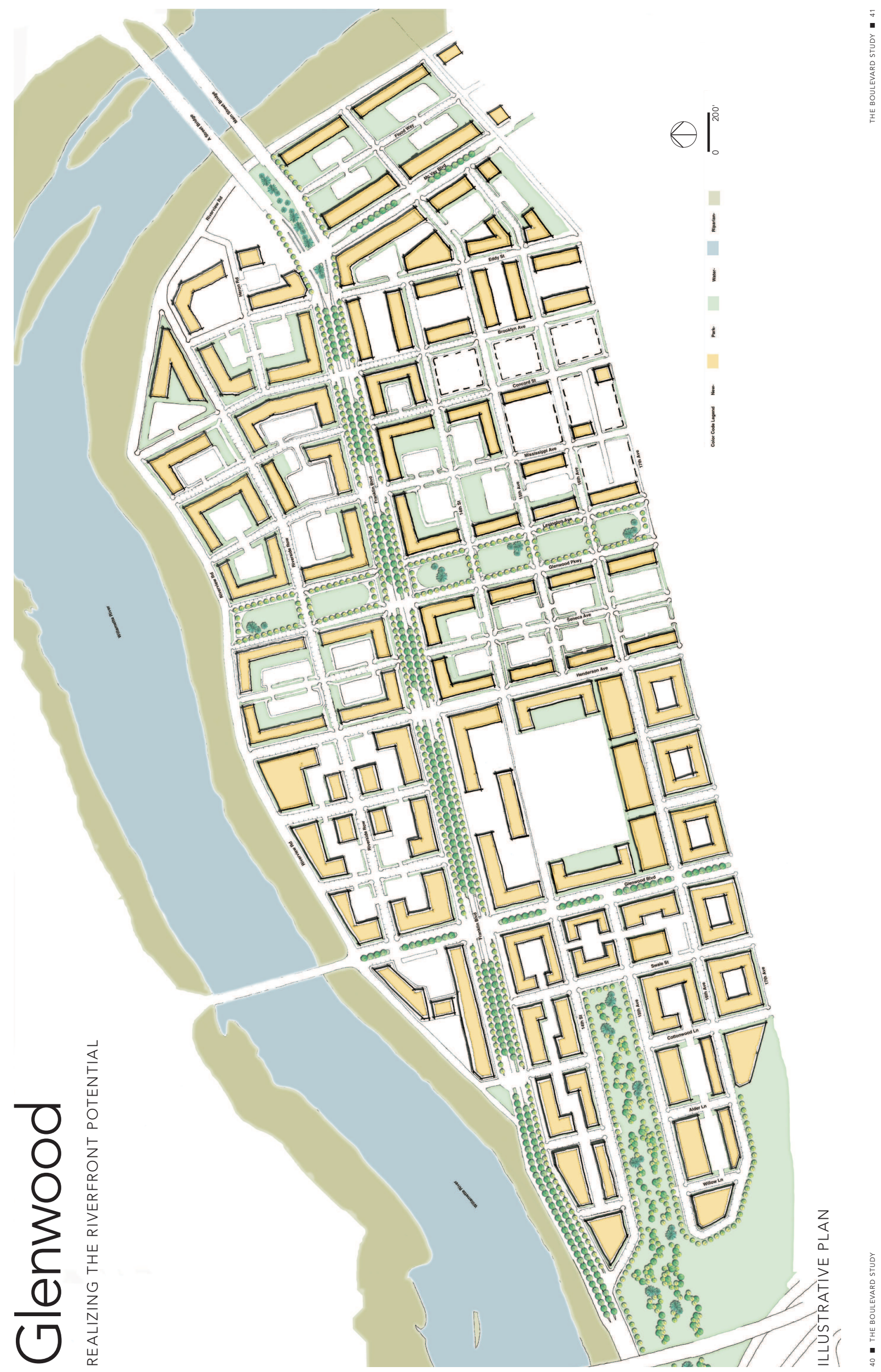




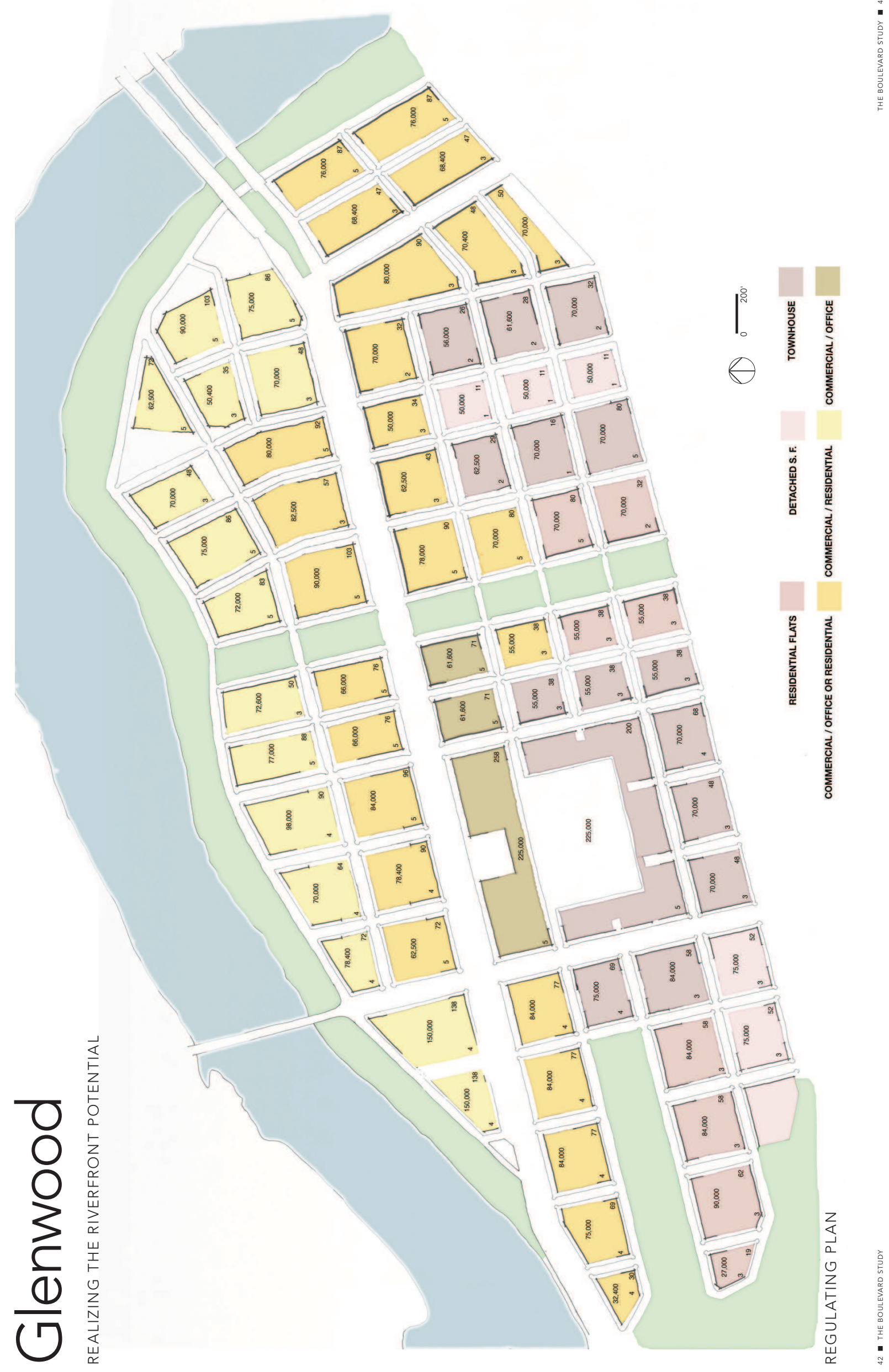



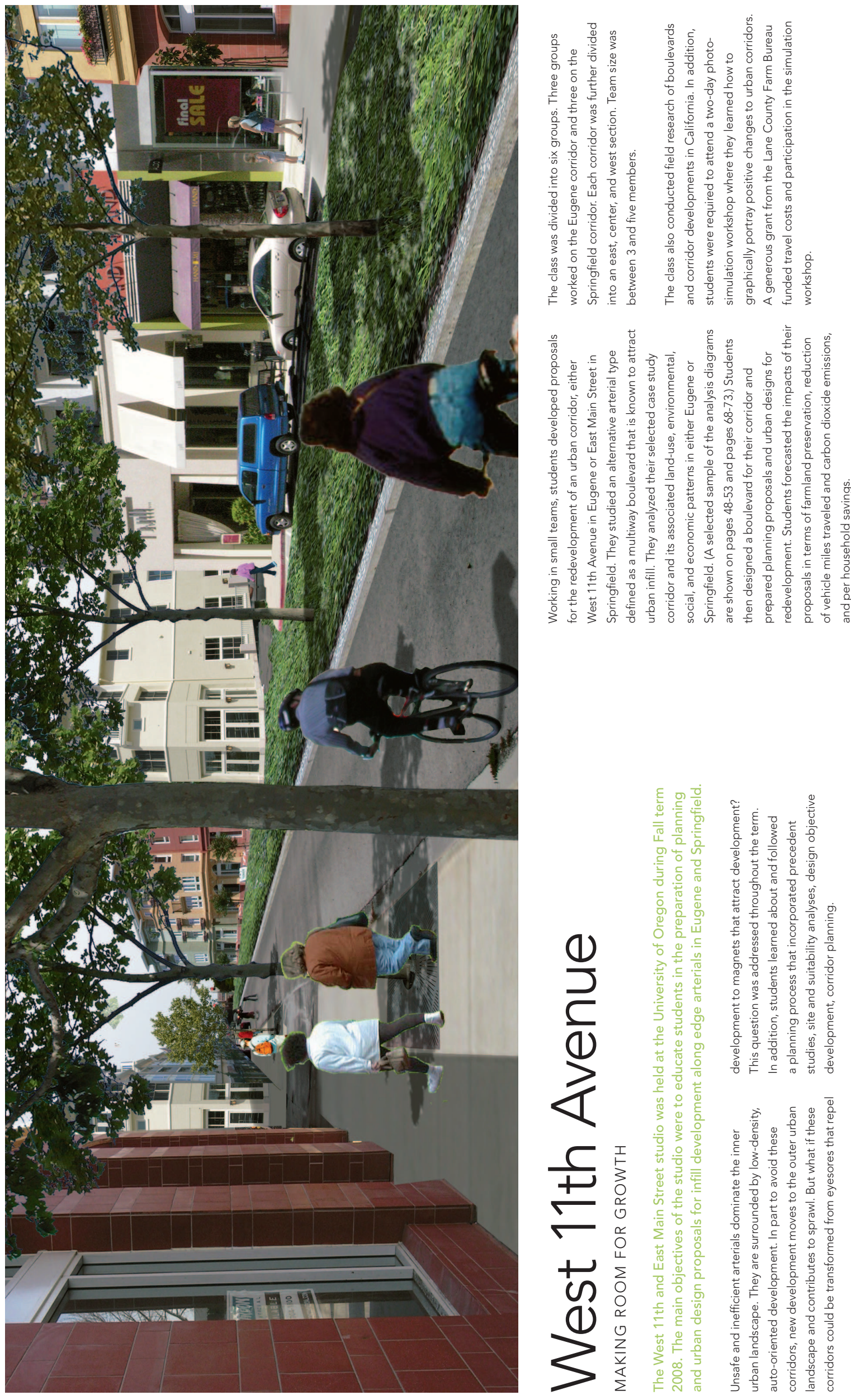


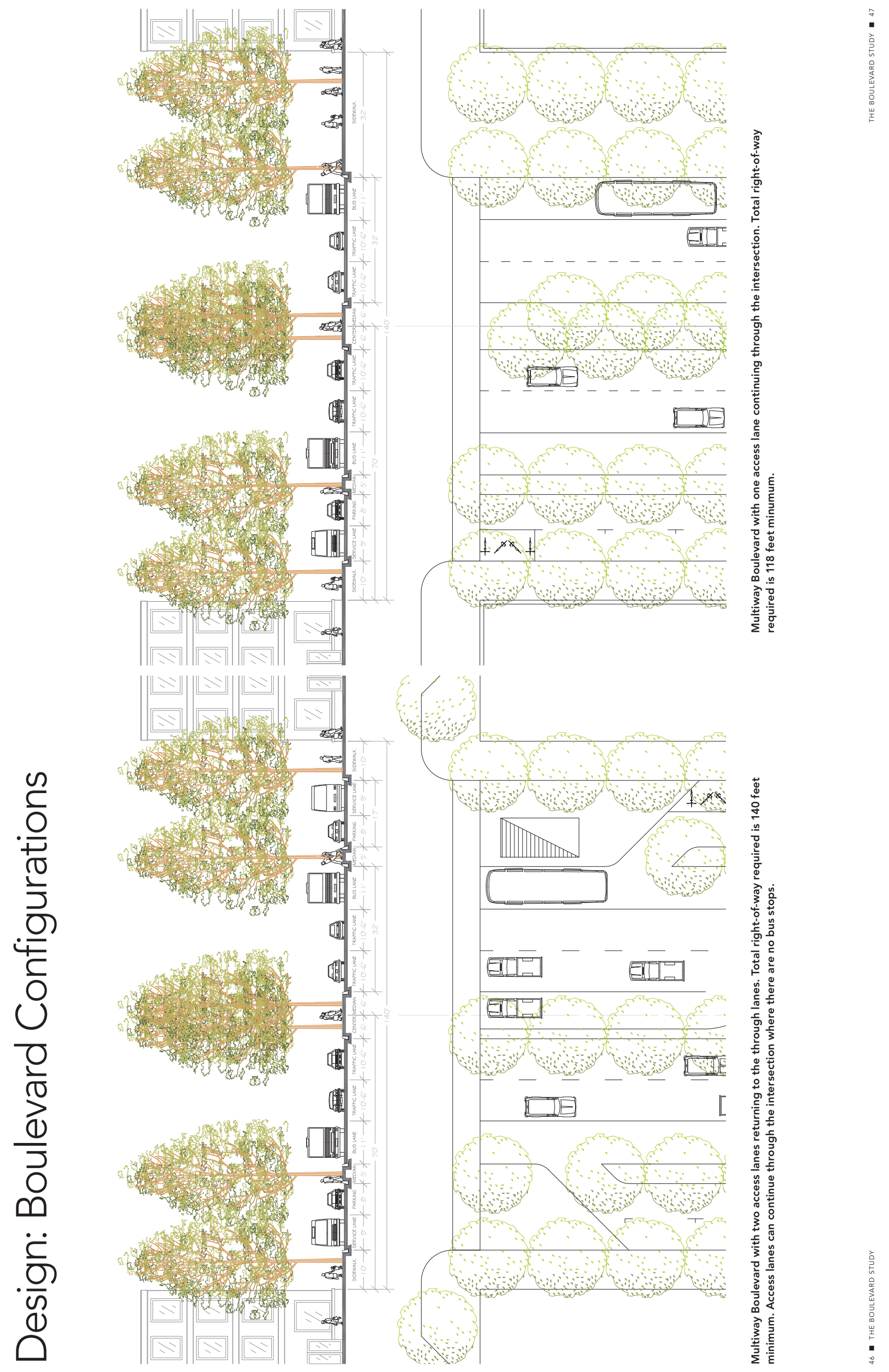



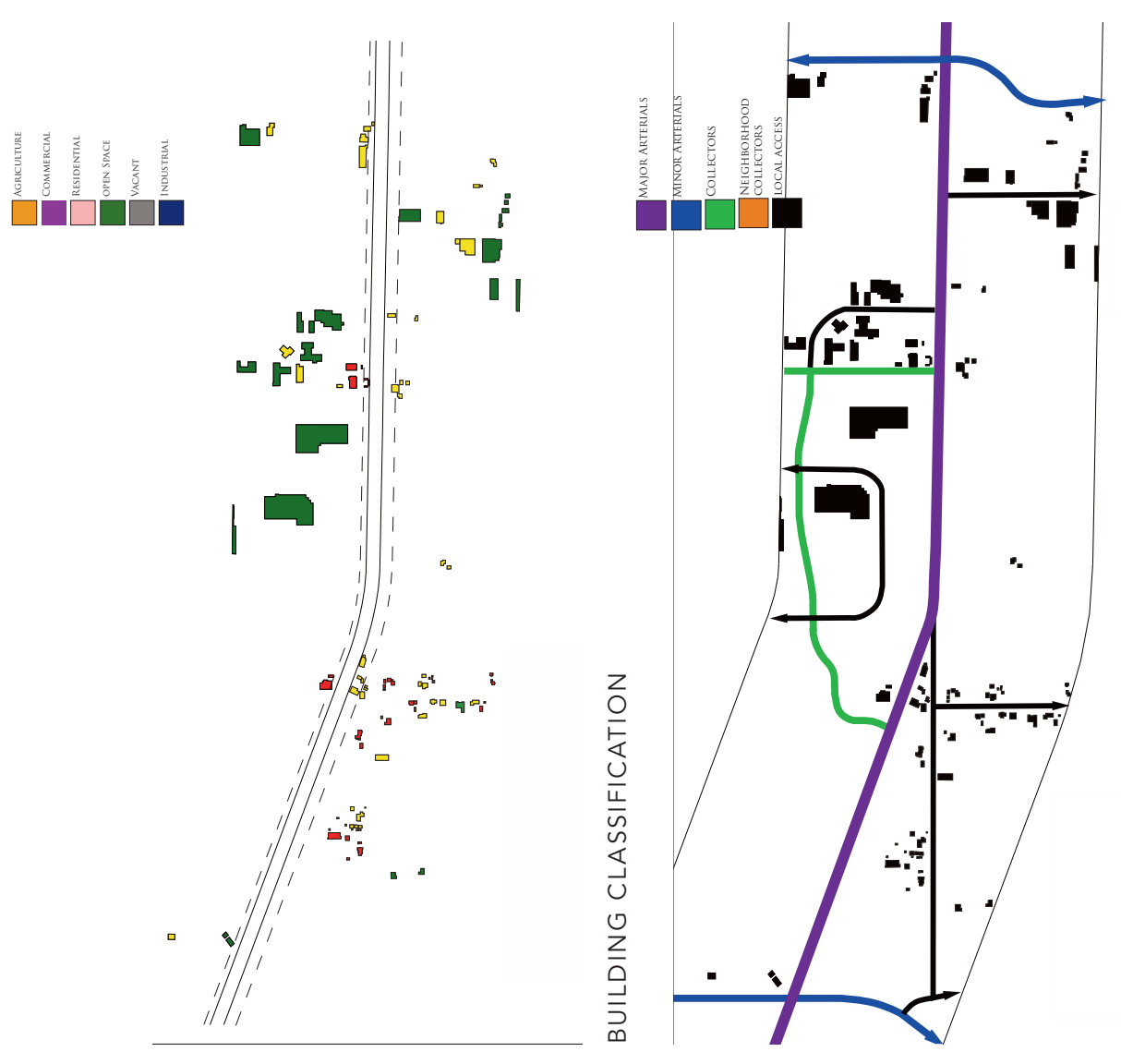

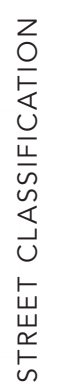
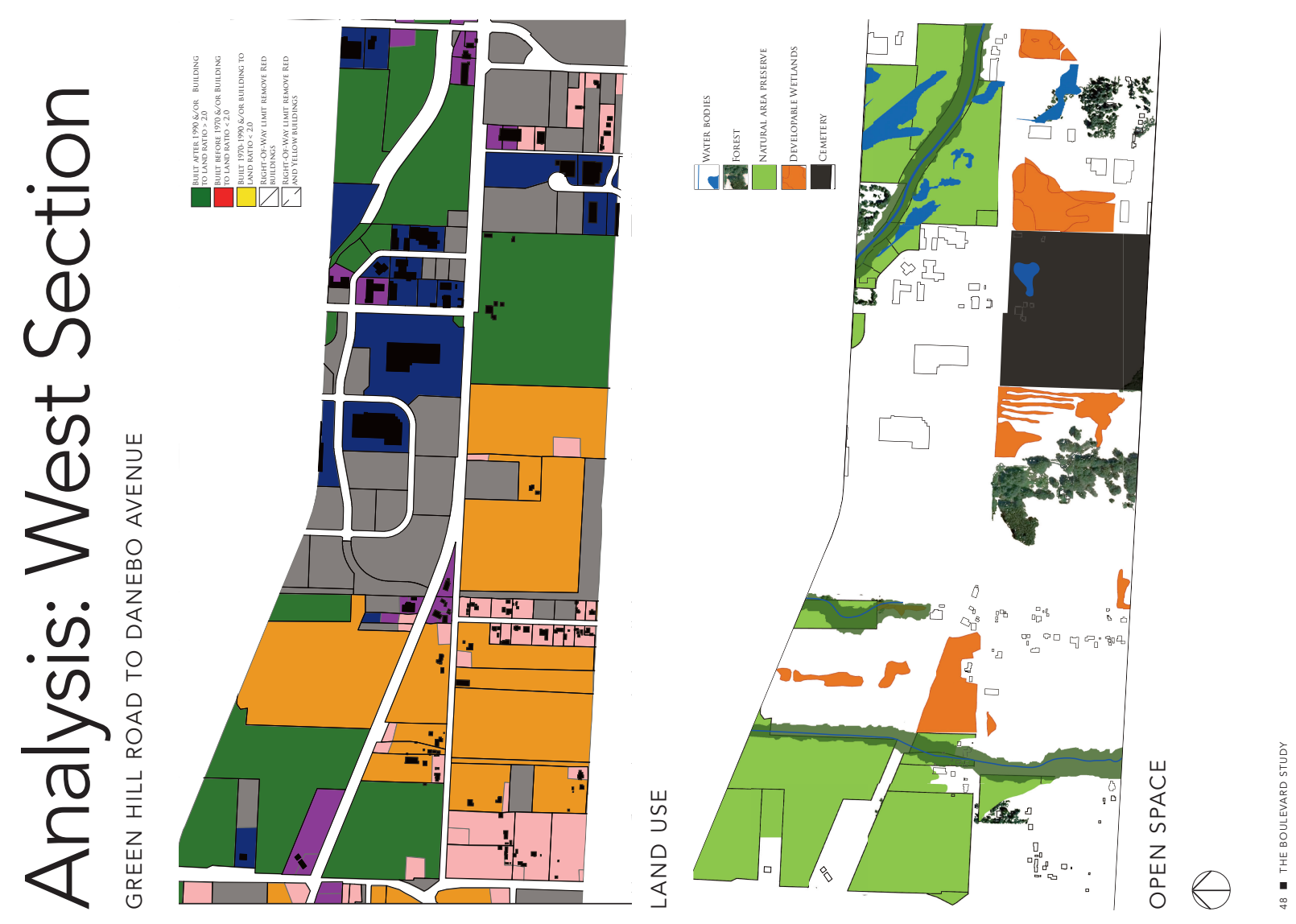


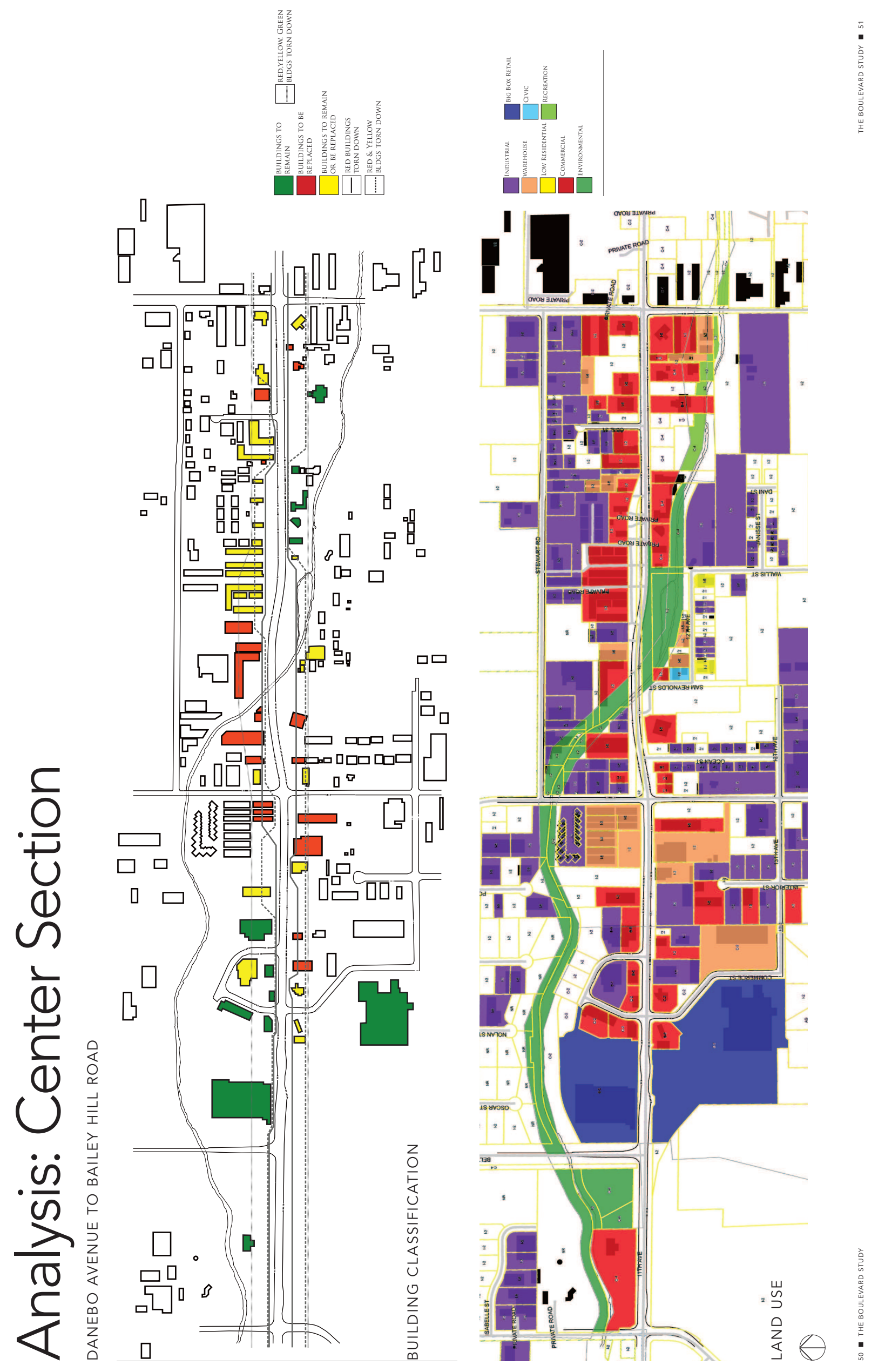



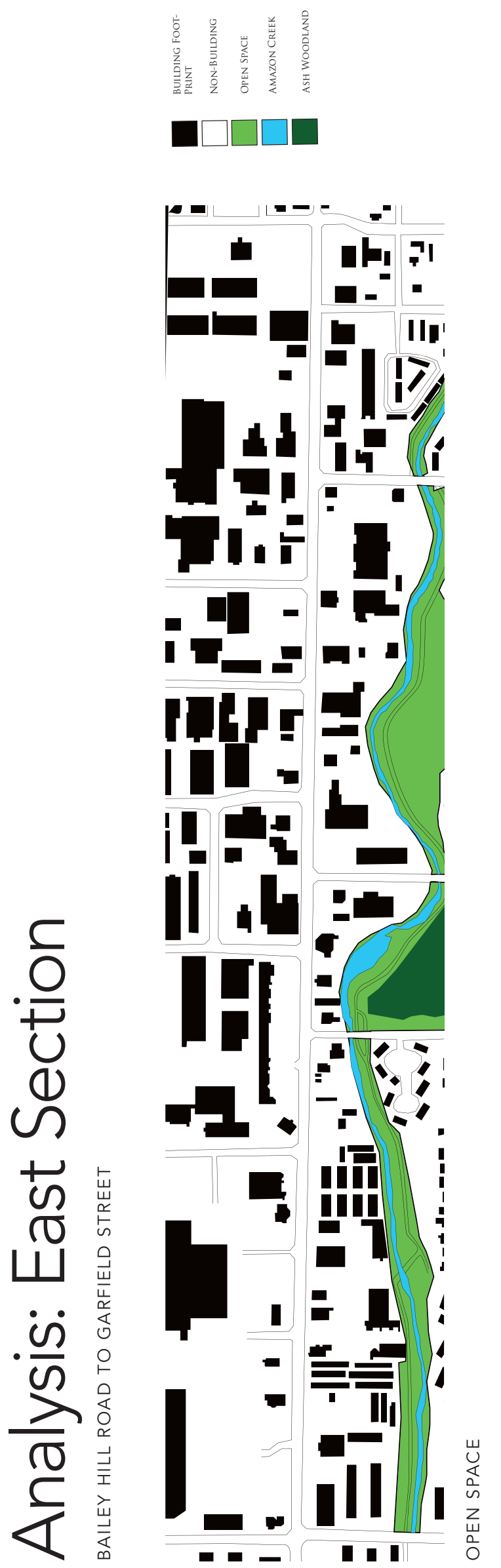
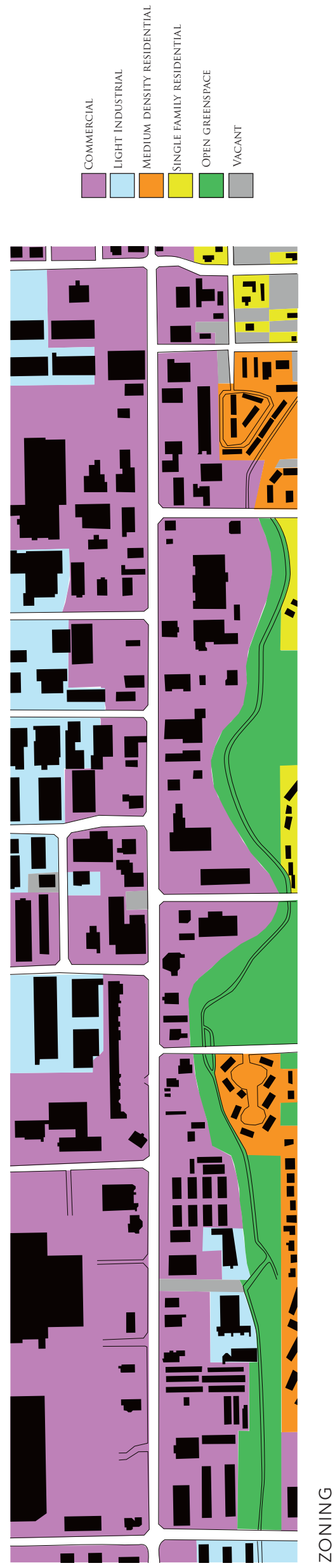

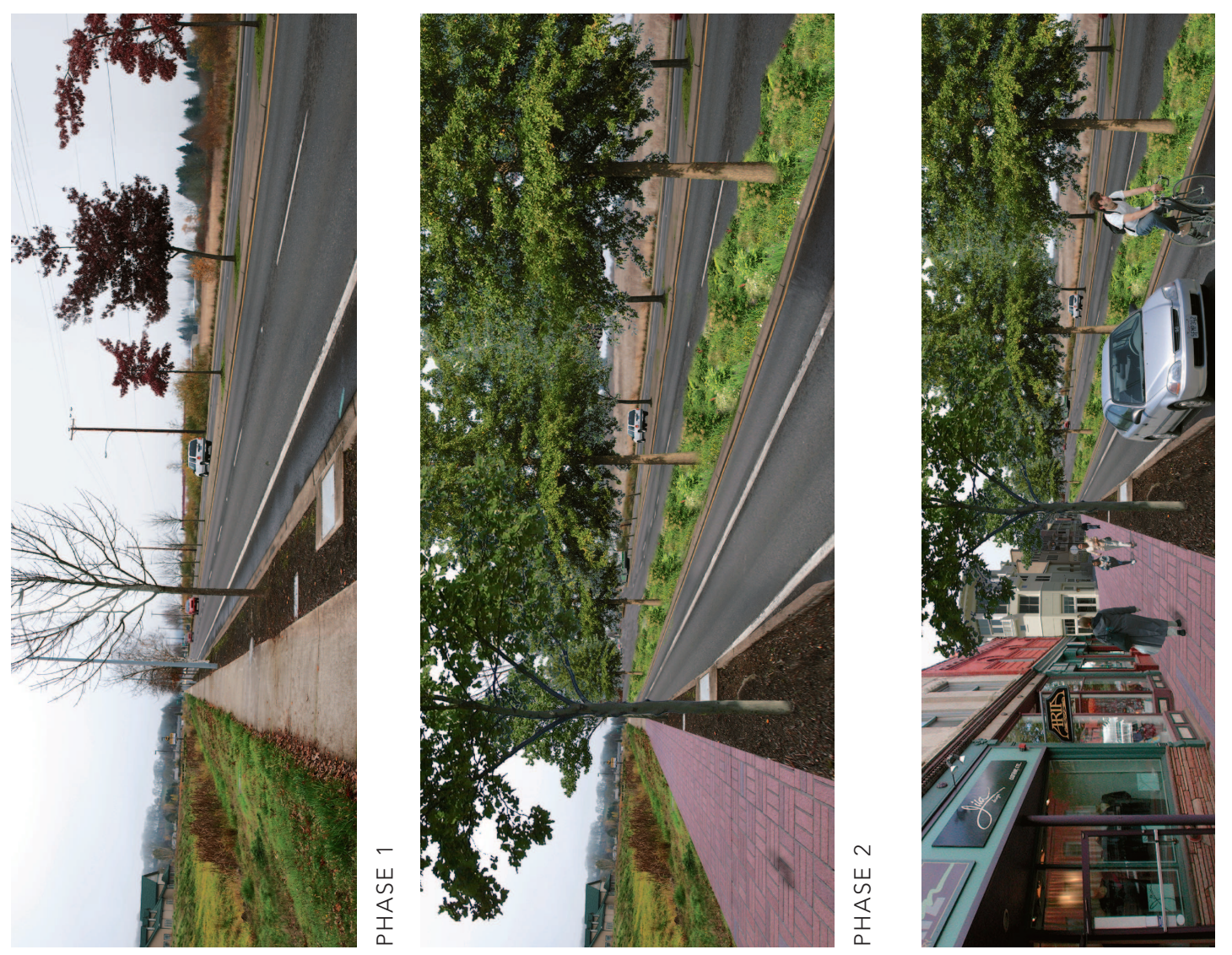

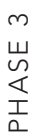

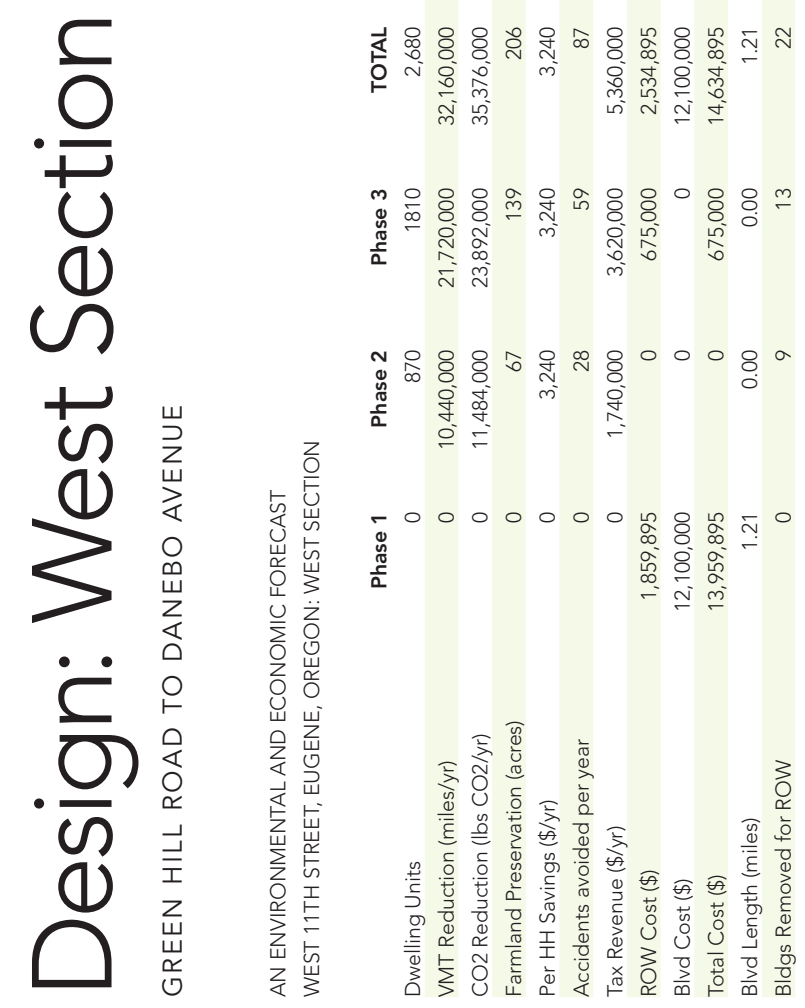




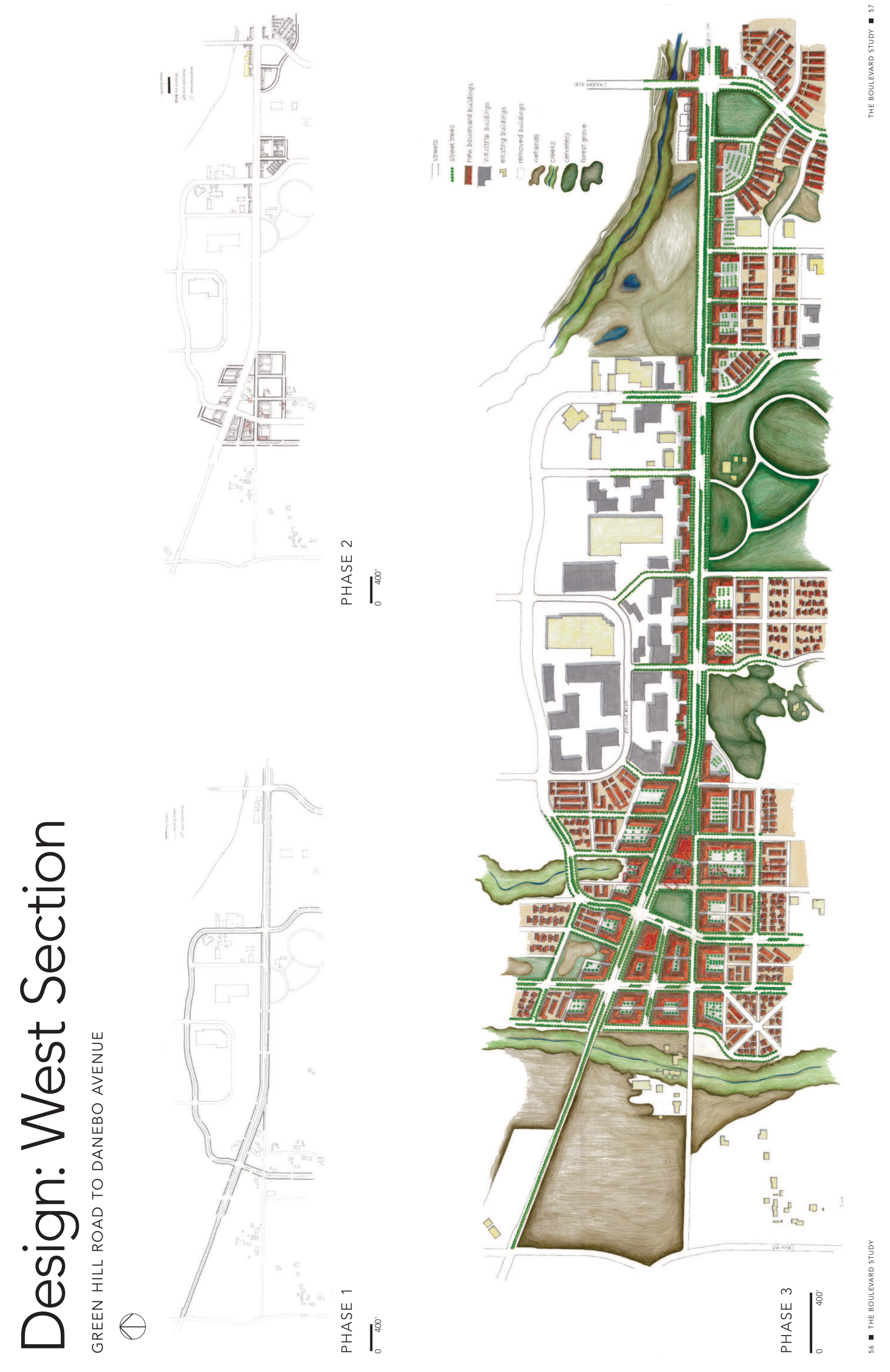



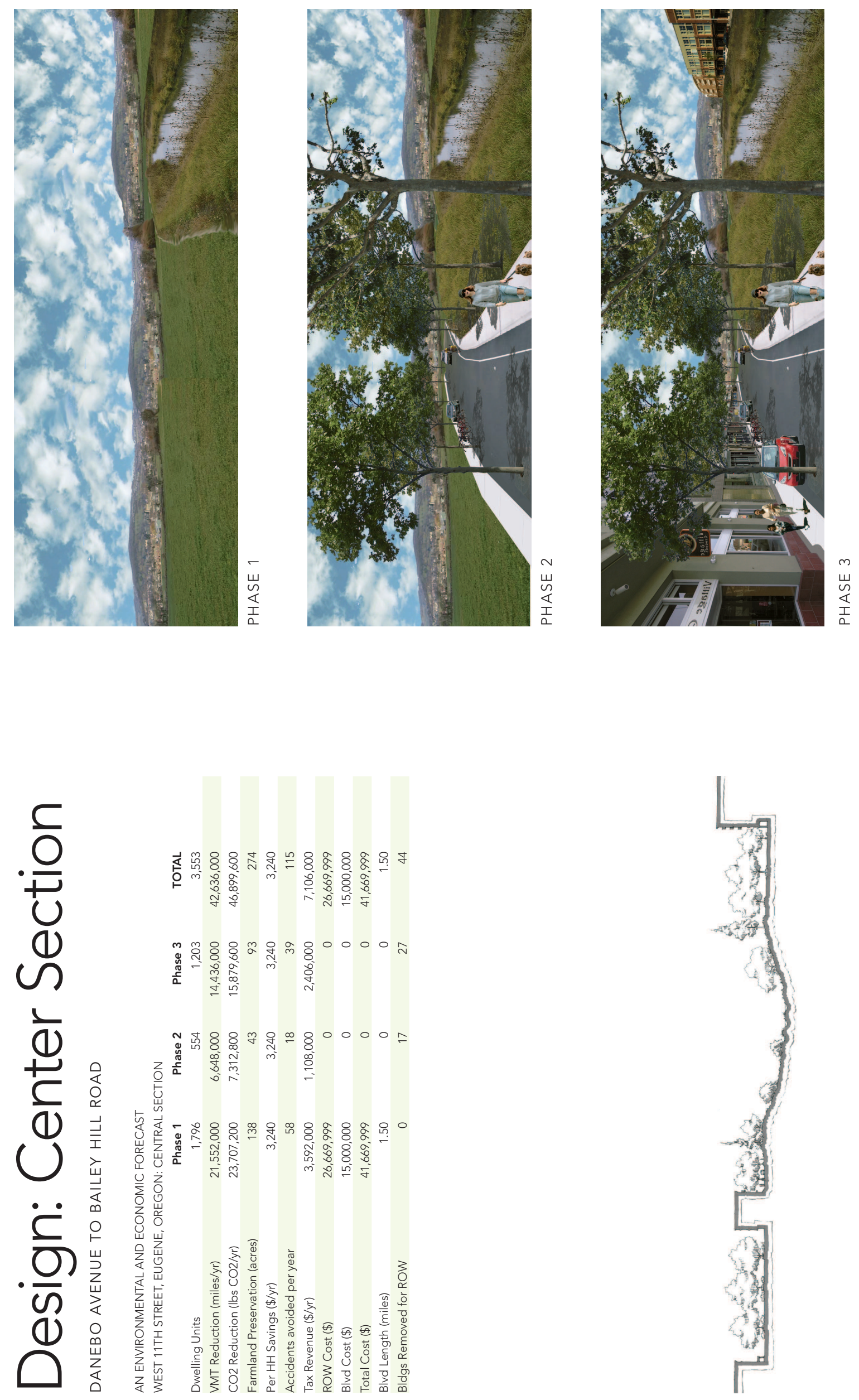

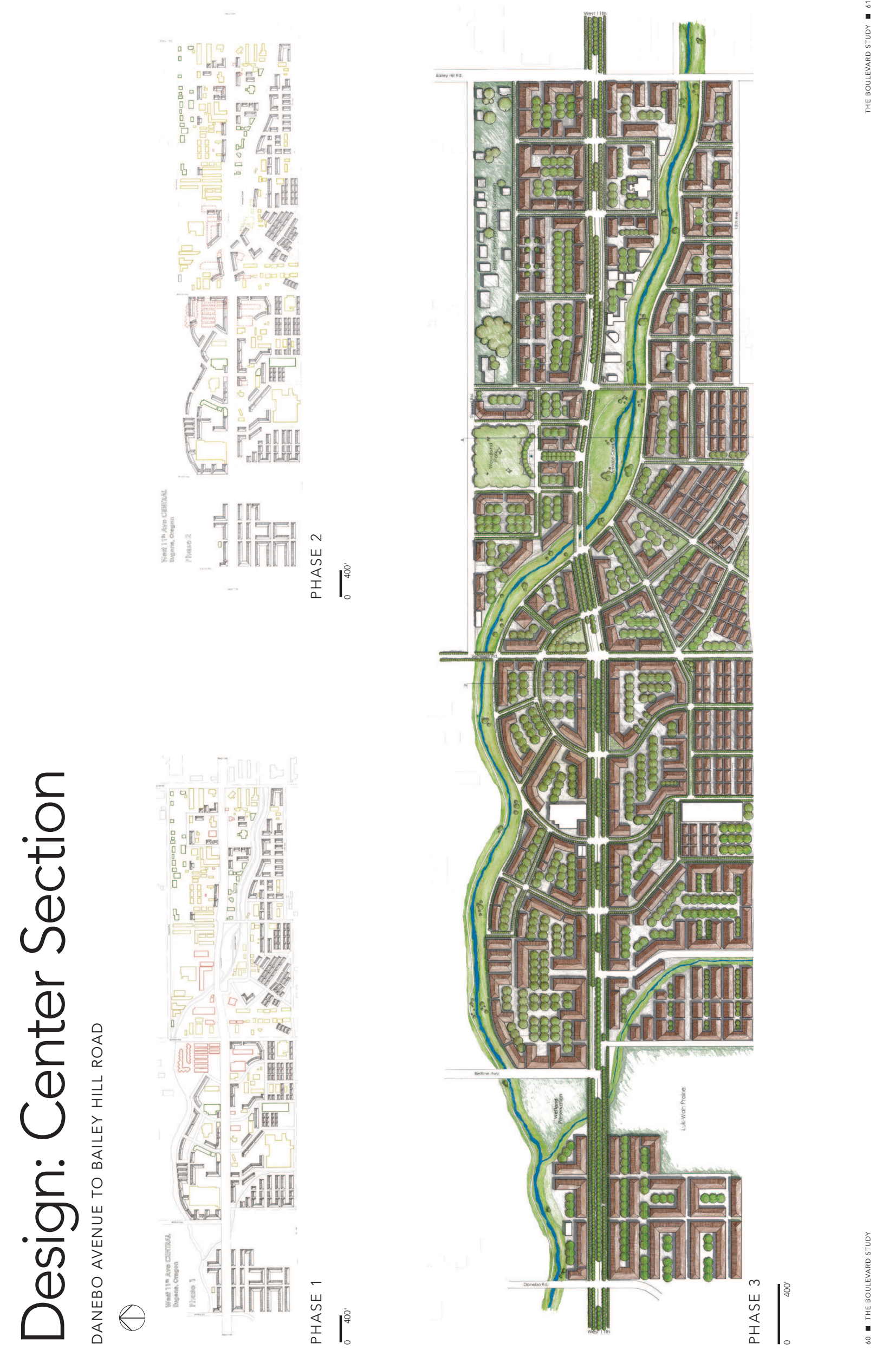

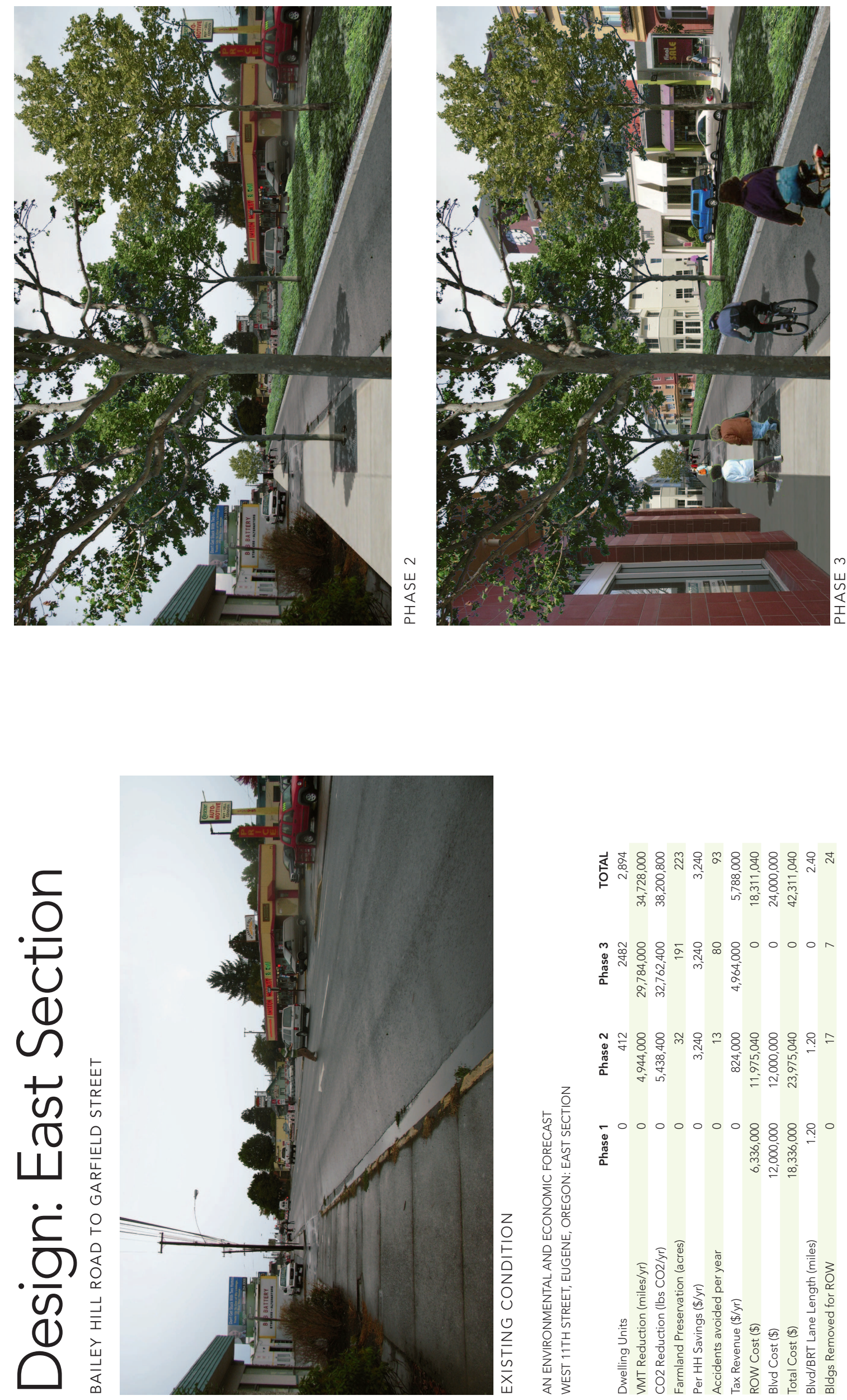

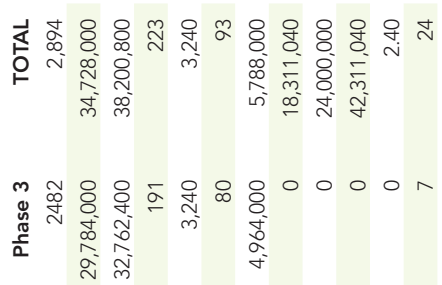

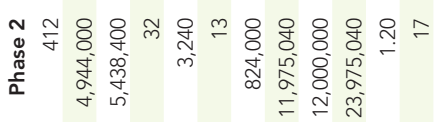

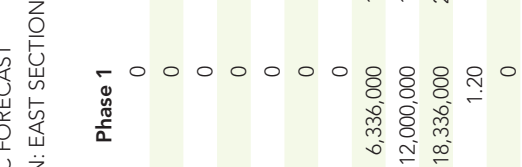

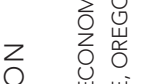

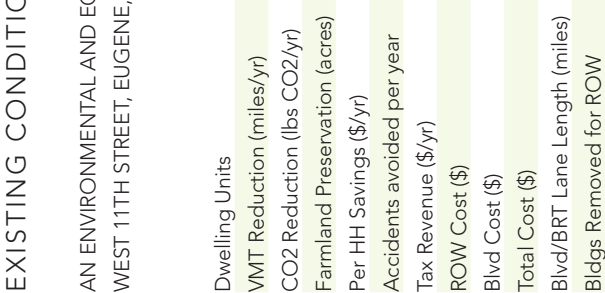




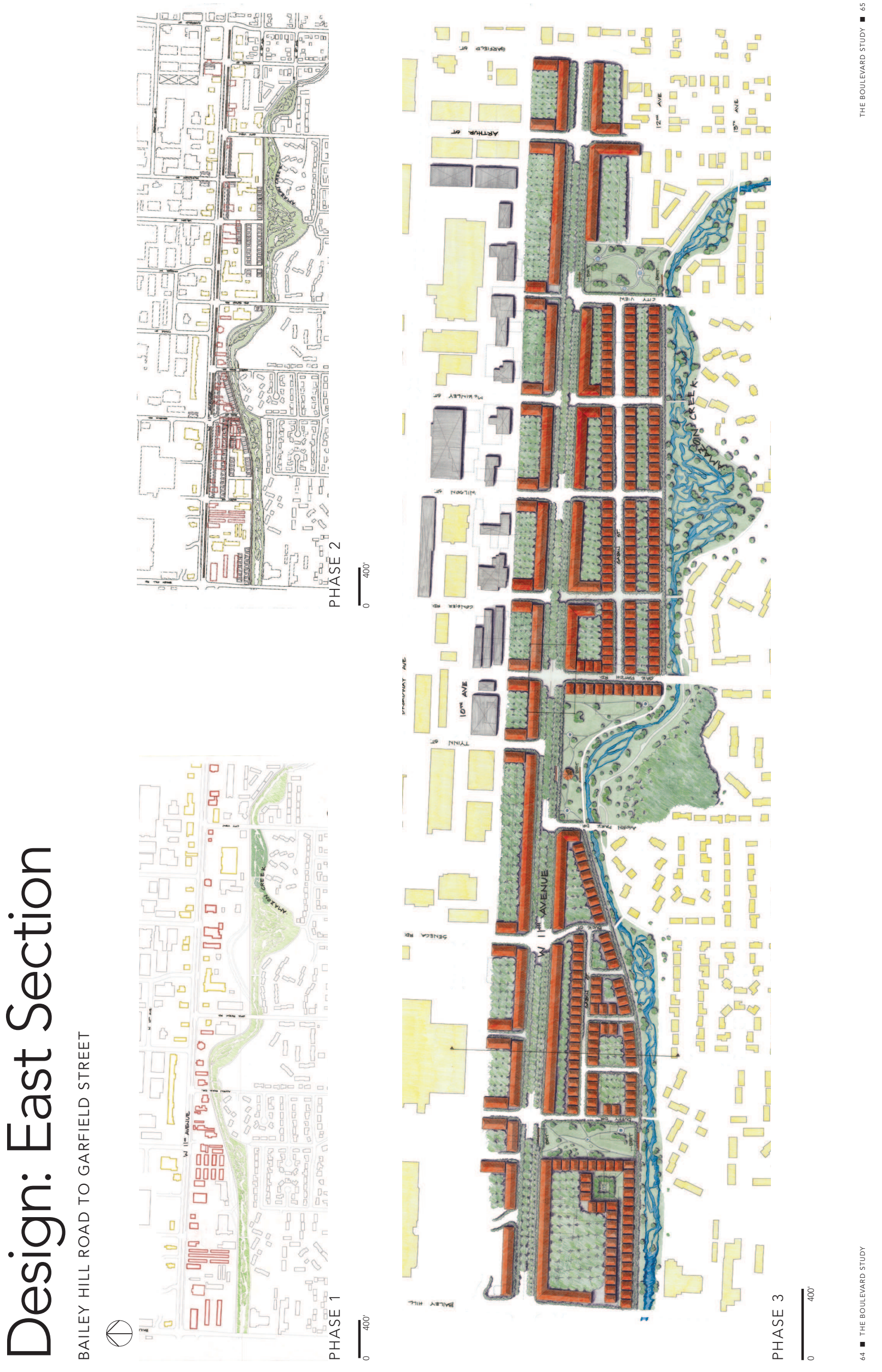




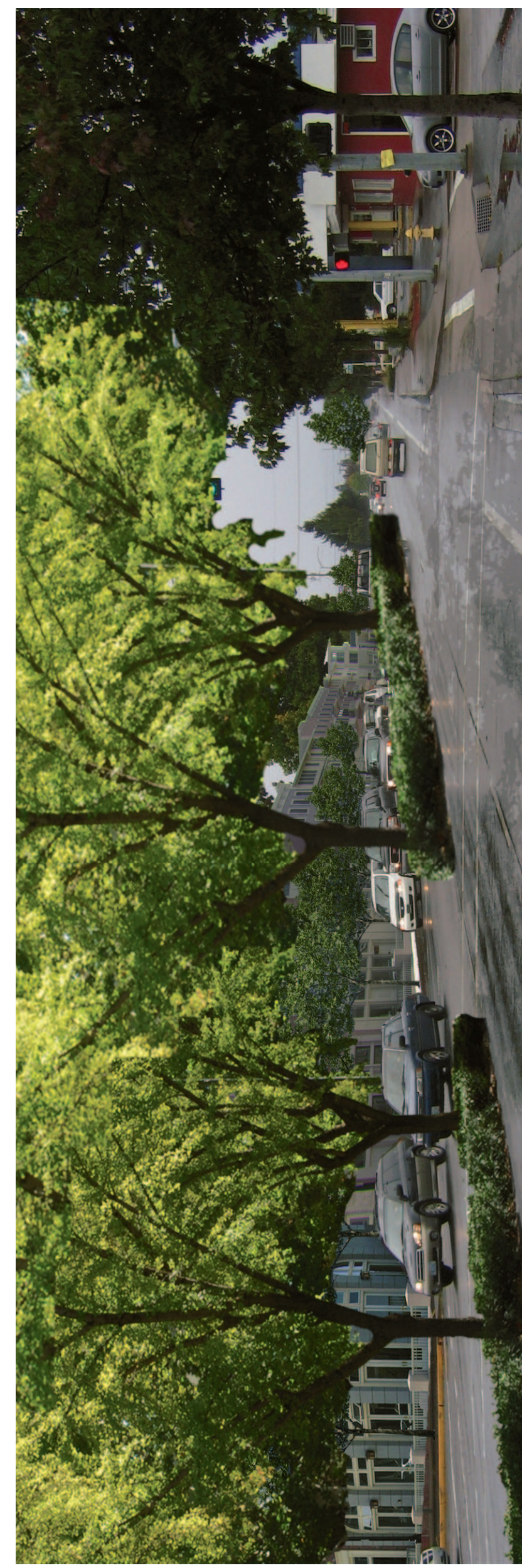

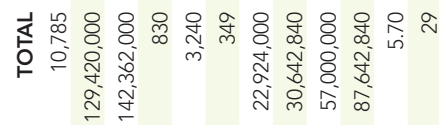

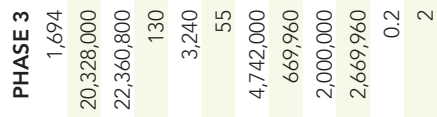

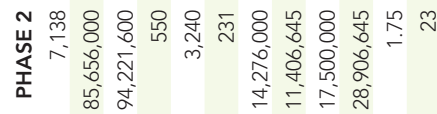

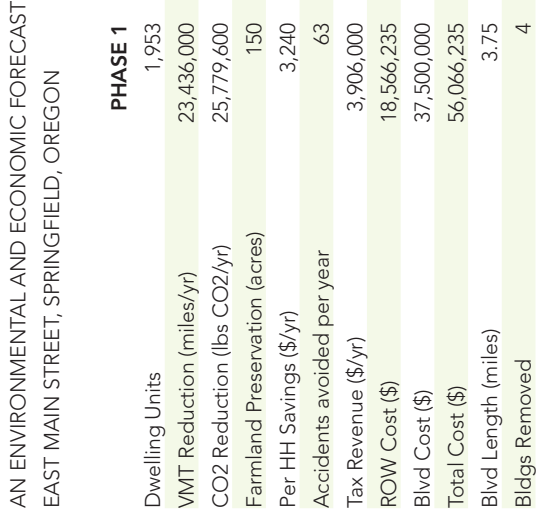



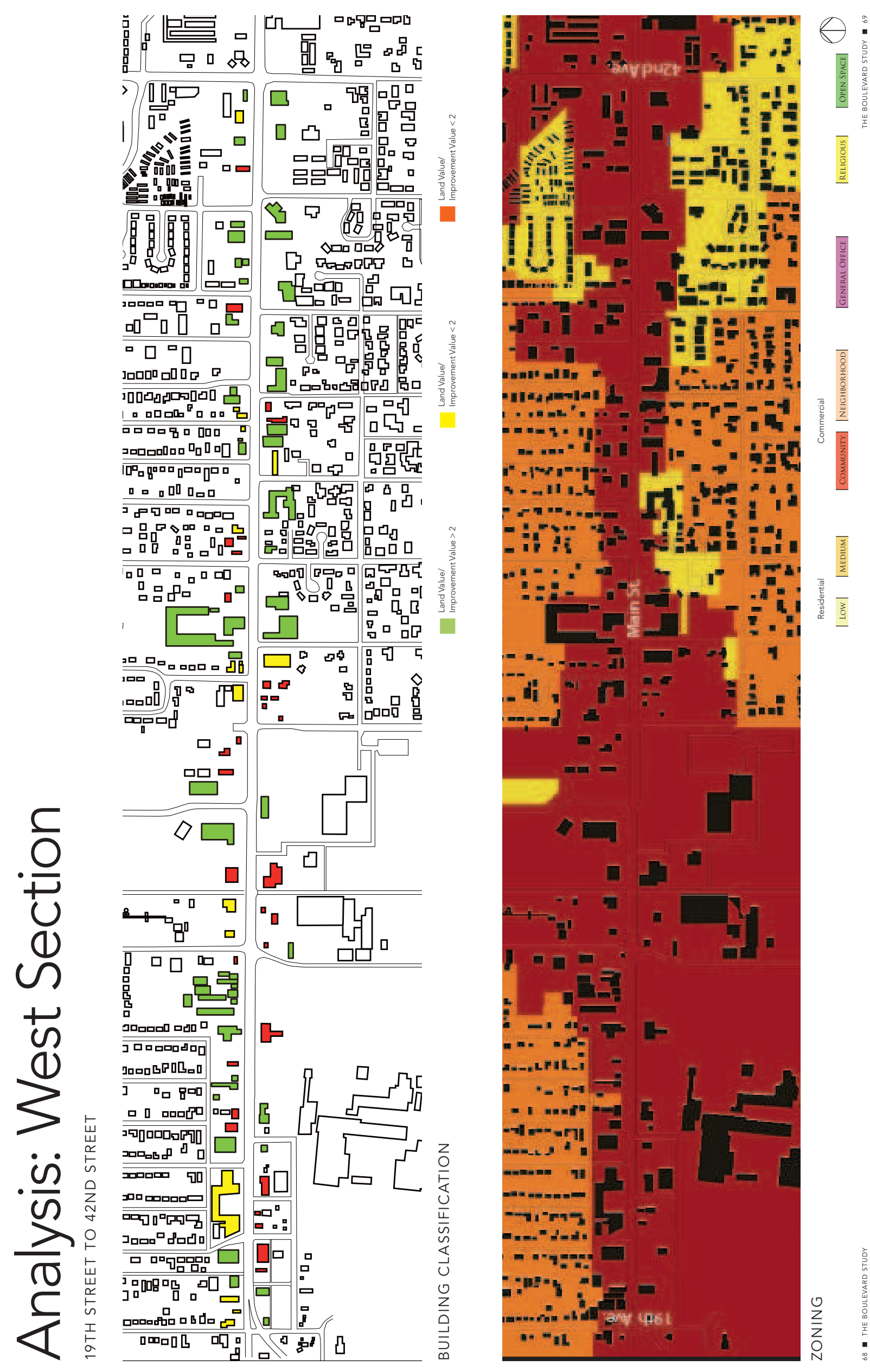

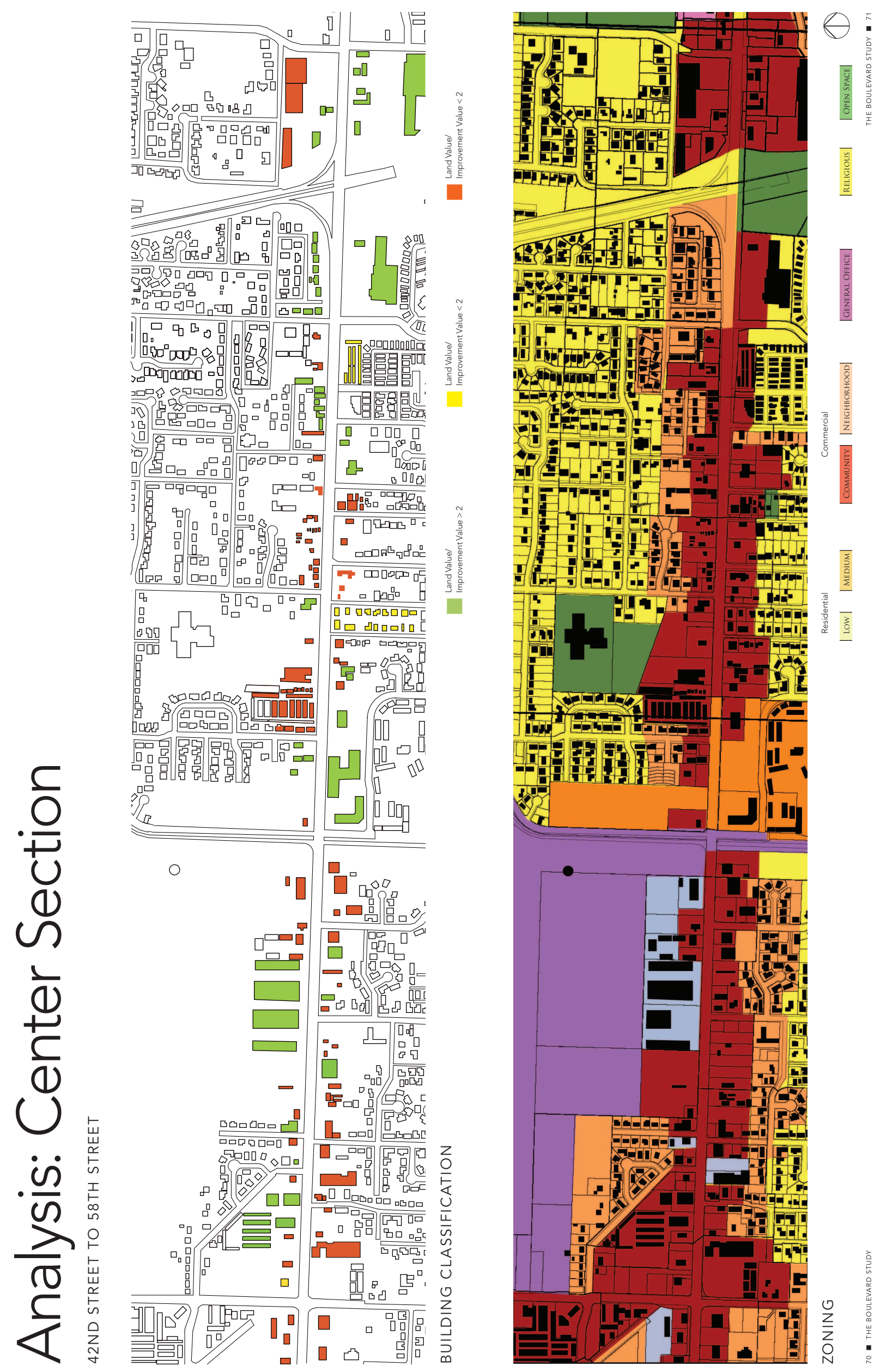


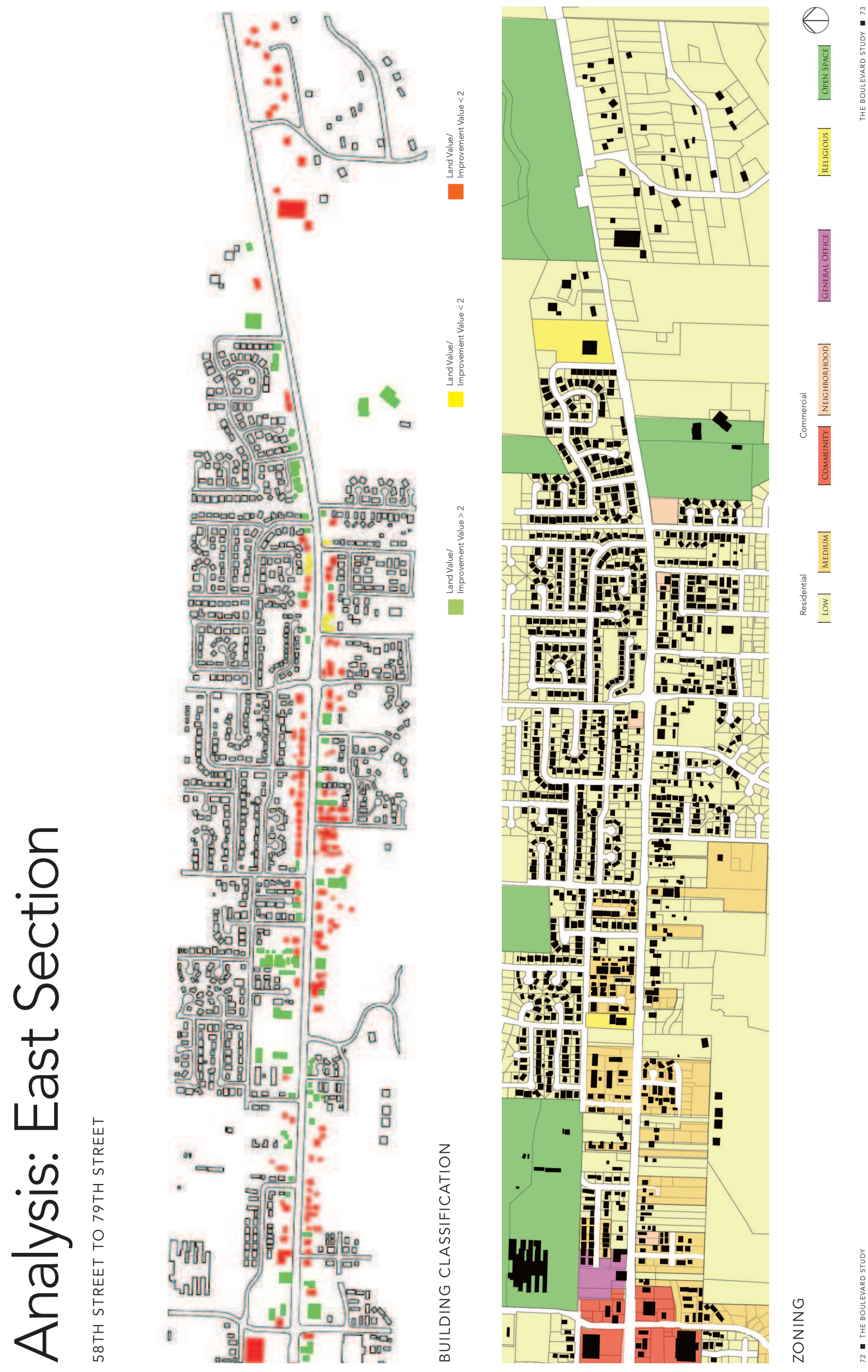



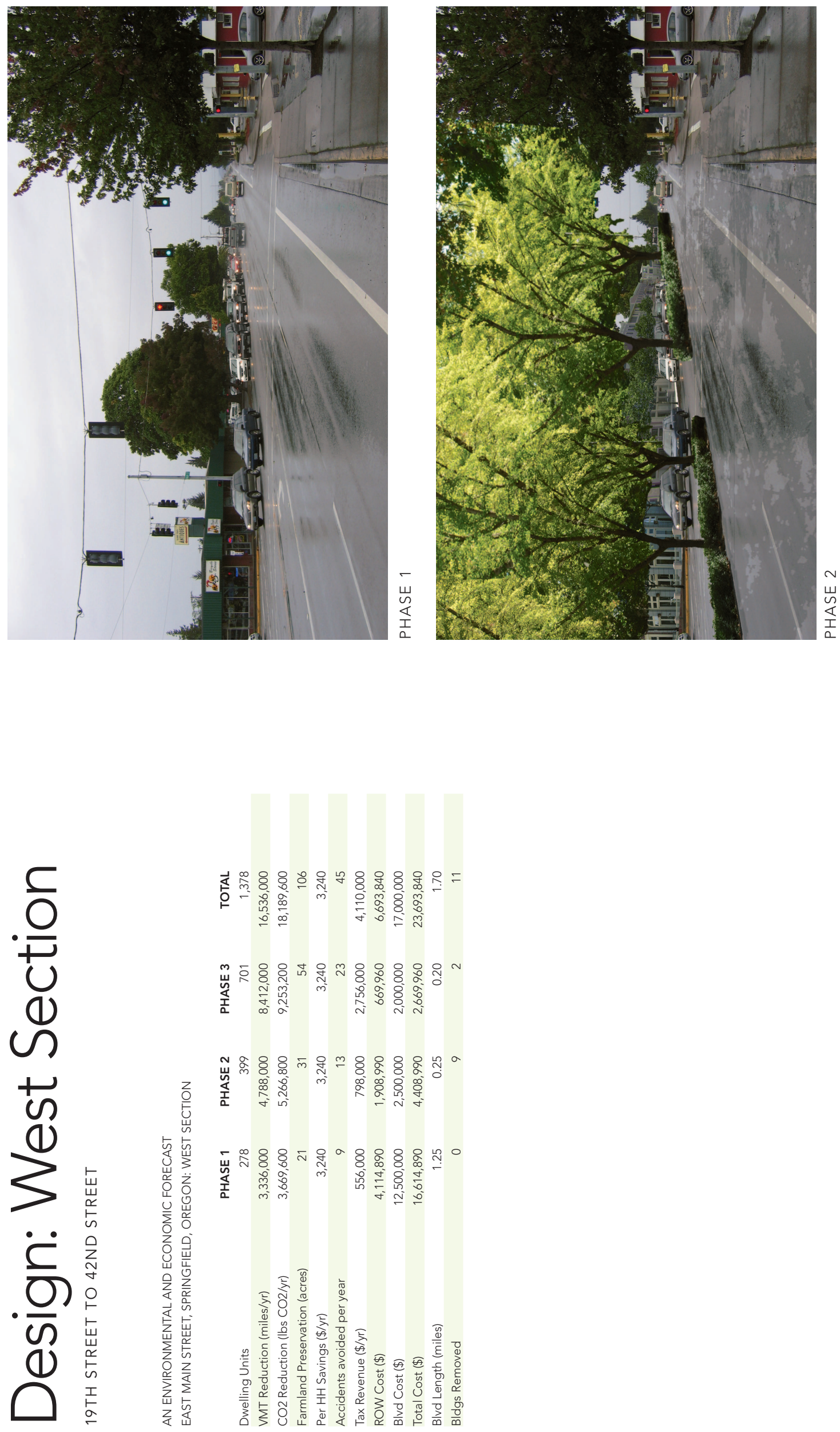

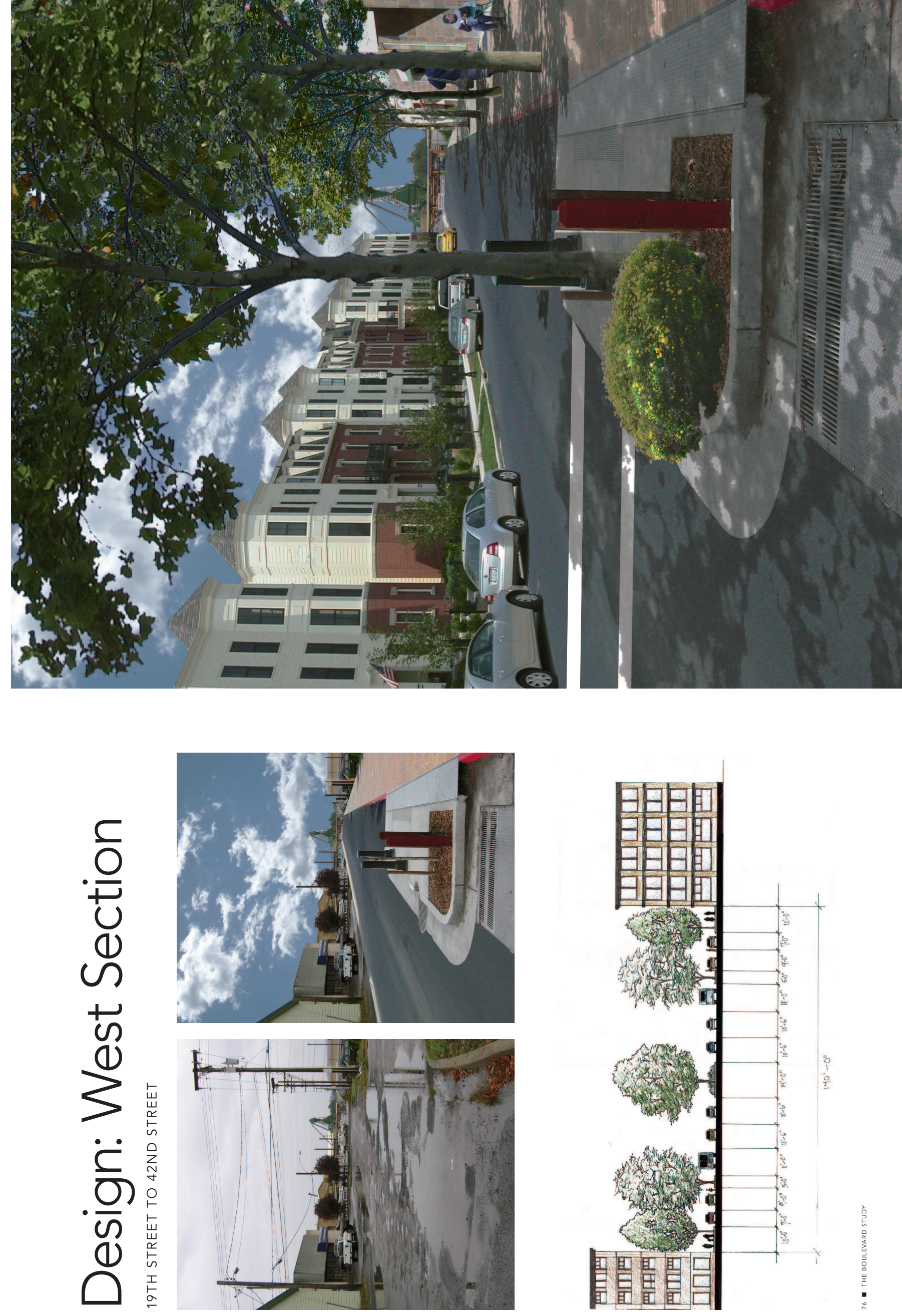


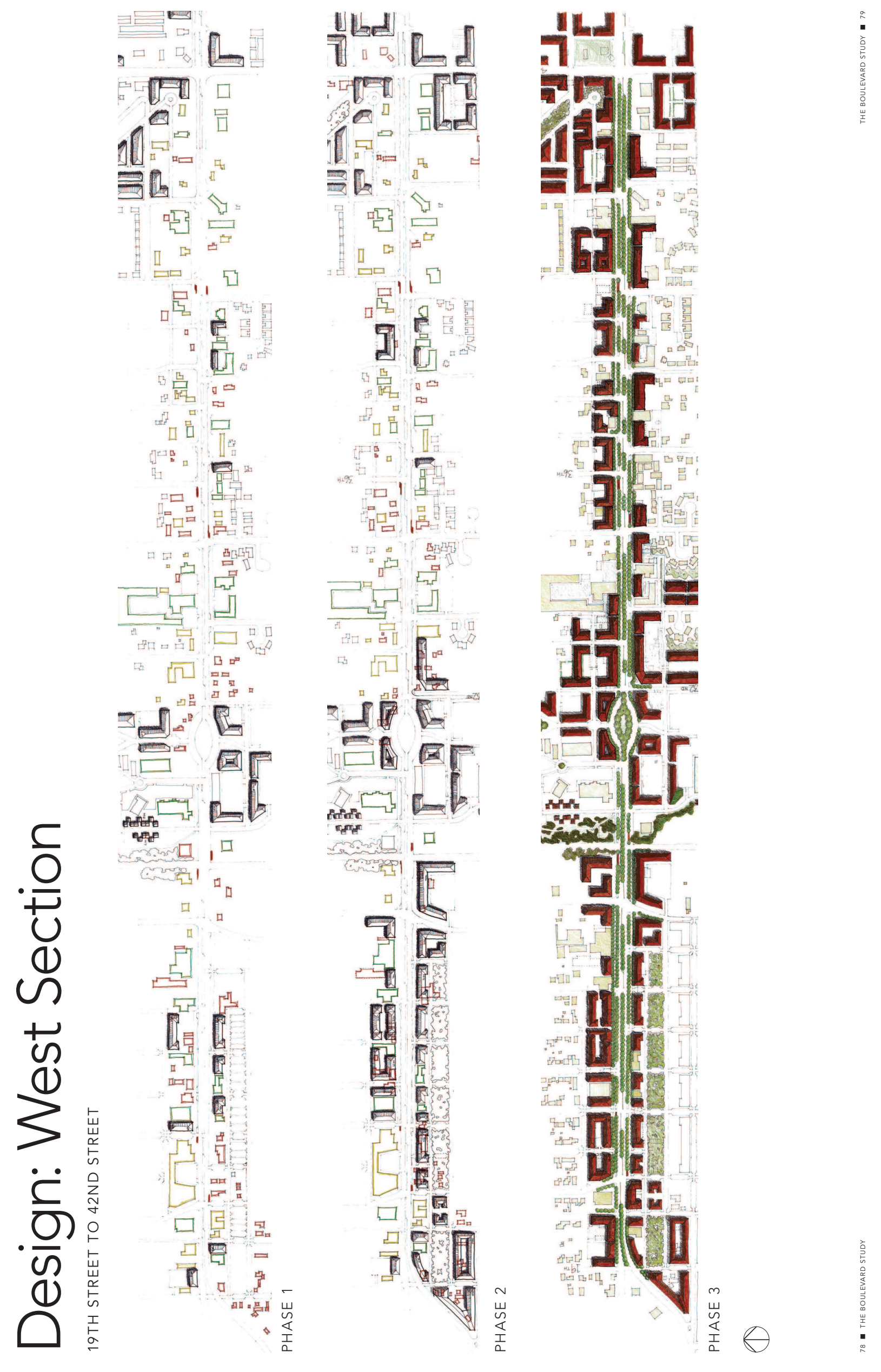



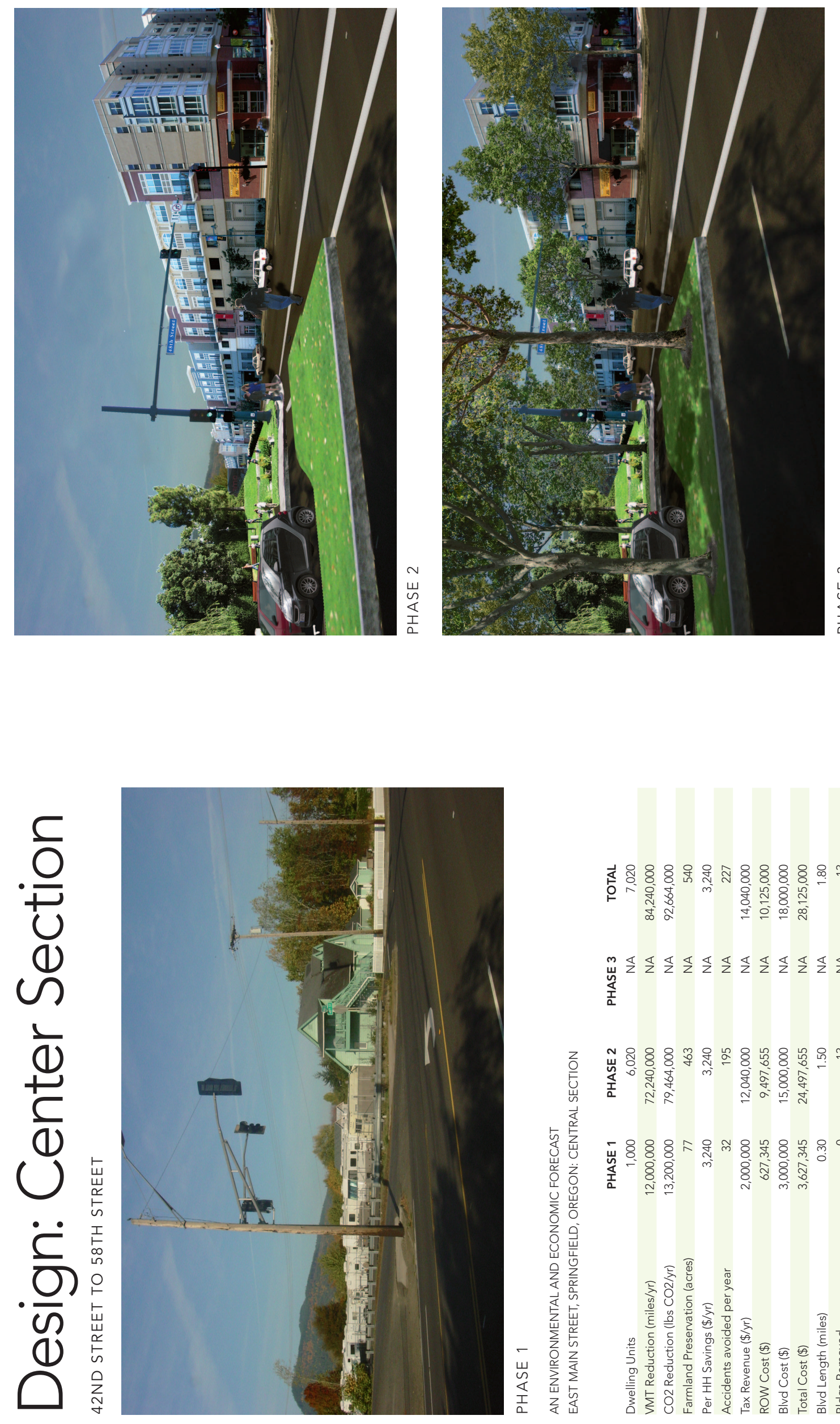

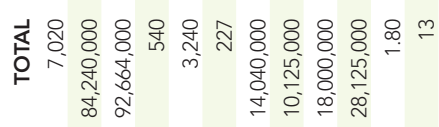

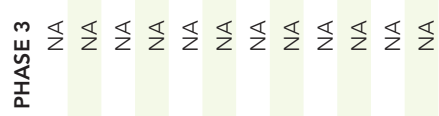

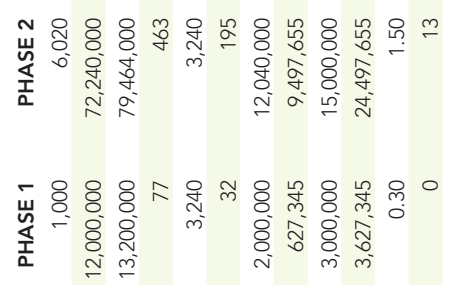



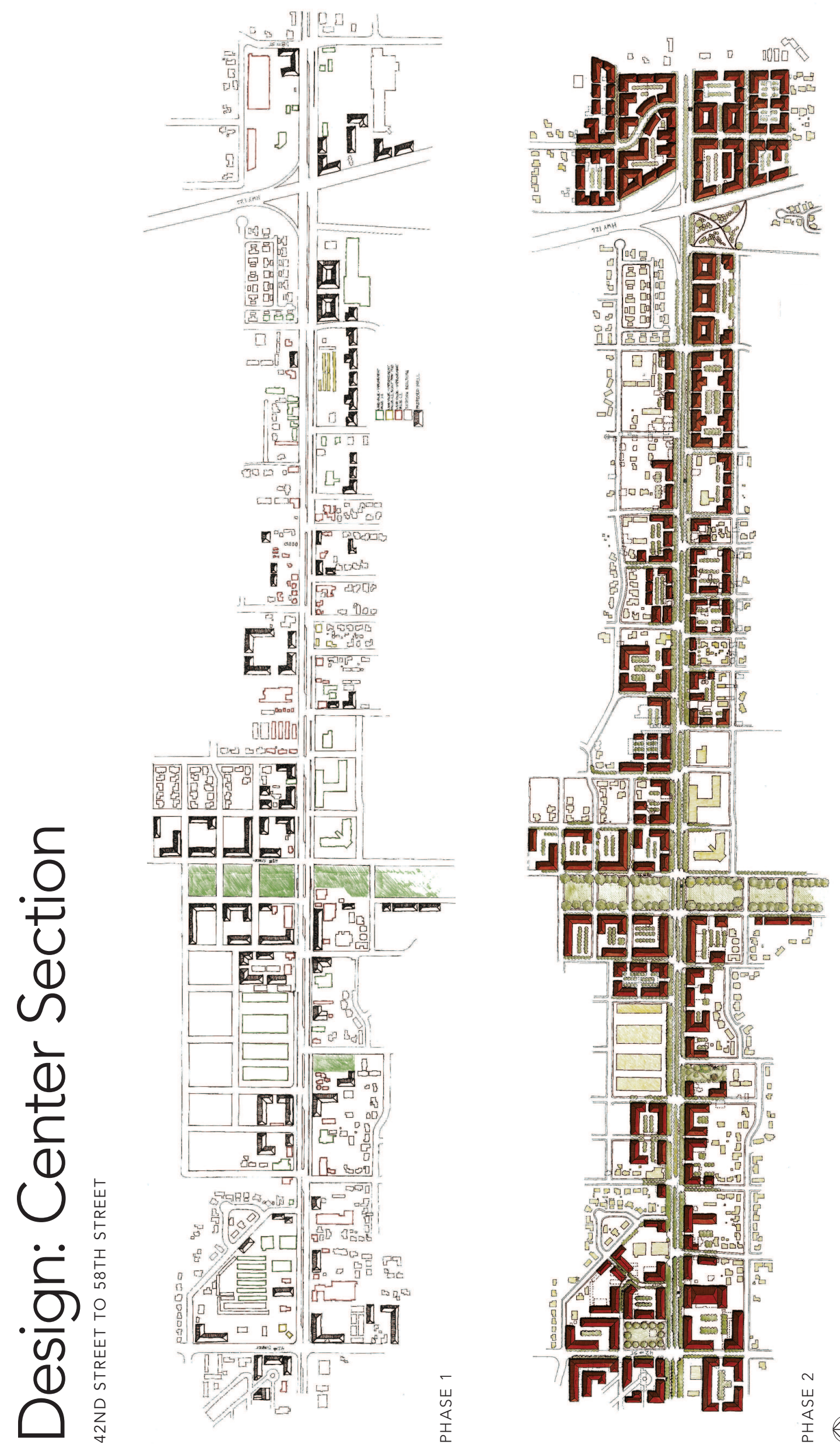

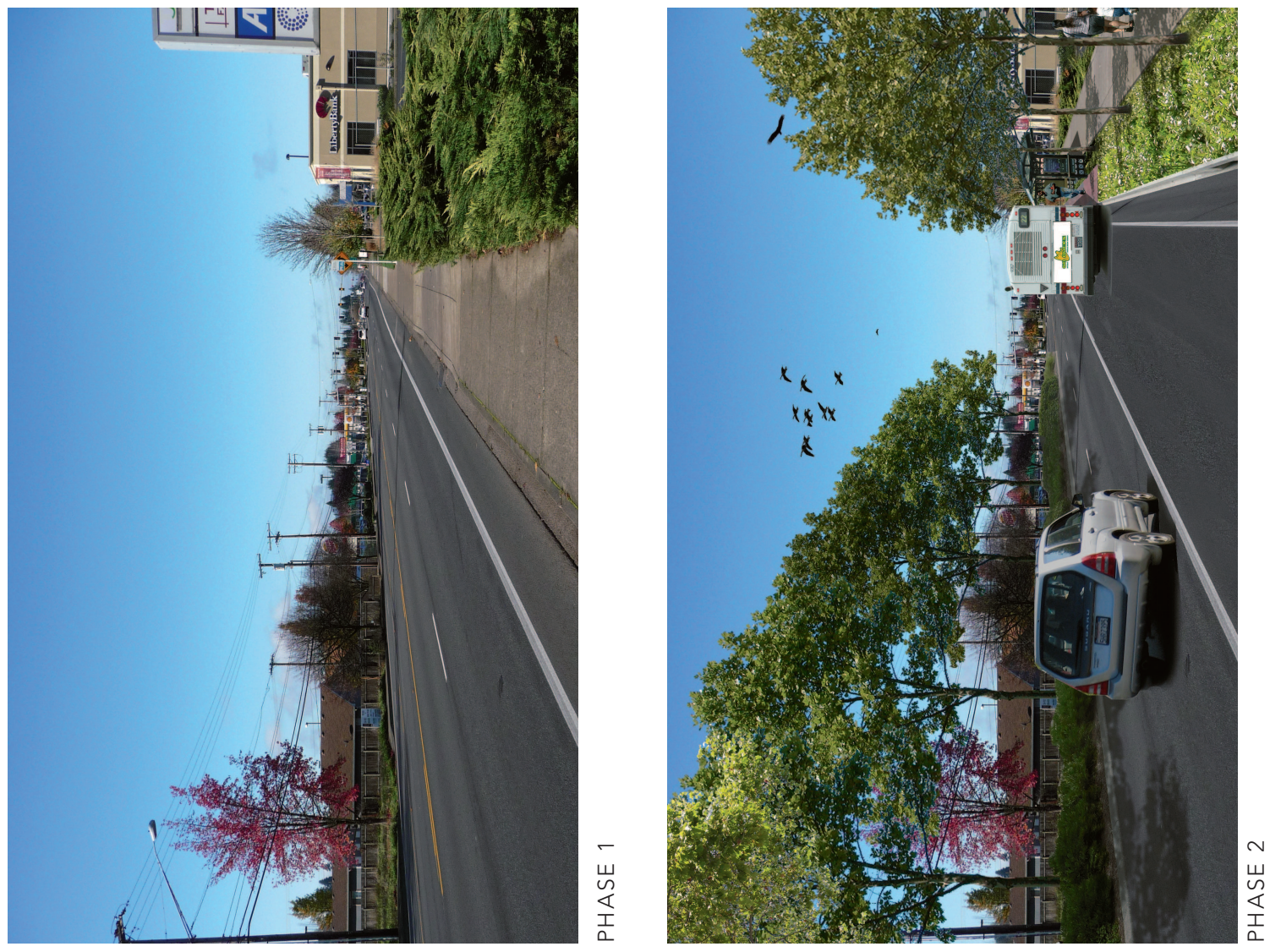

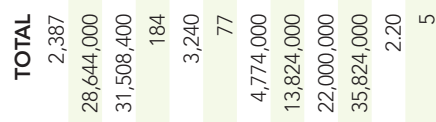

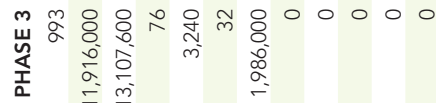

(1)

U

(

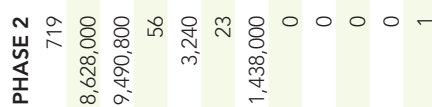

ᄂ

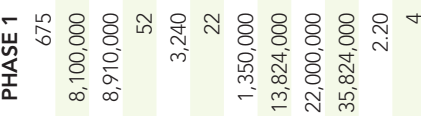

占 $\quad \sum_{0}^{\underline{u}}$

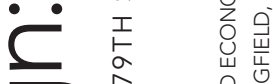

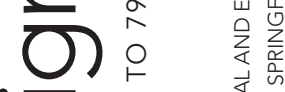

( 0 点 岦出

(1) 点 $\sum_{0}$

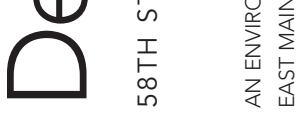





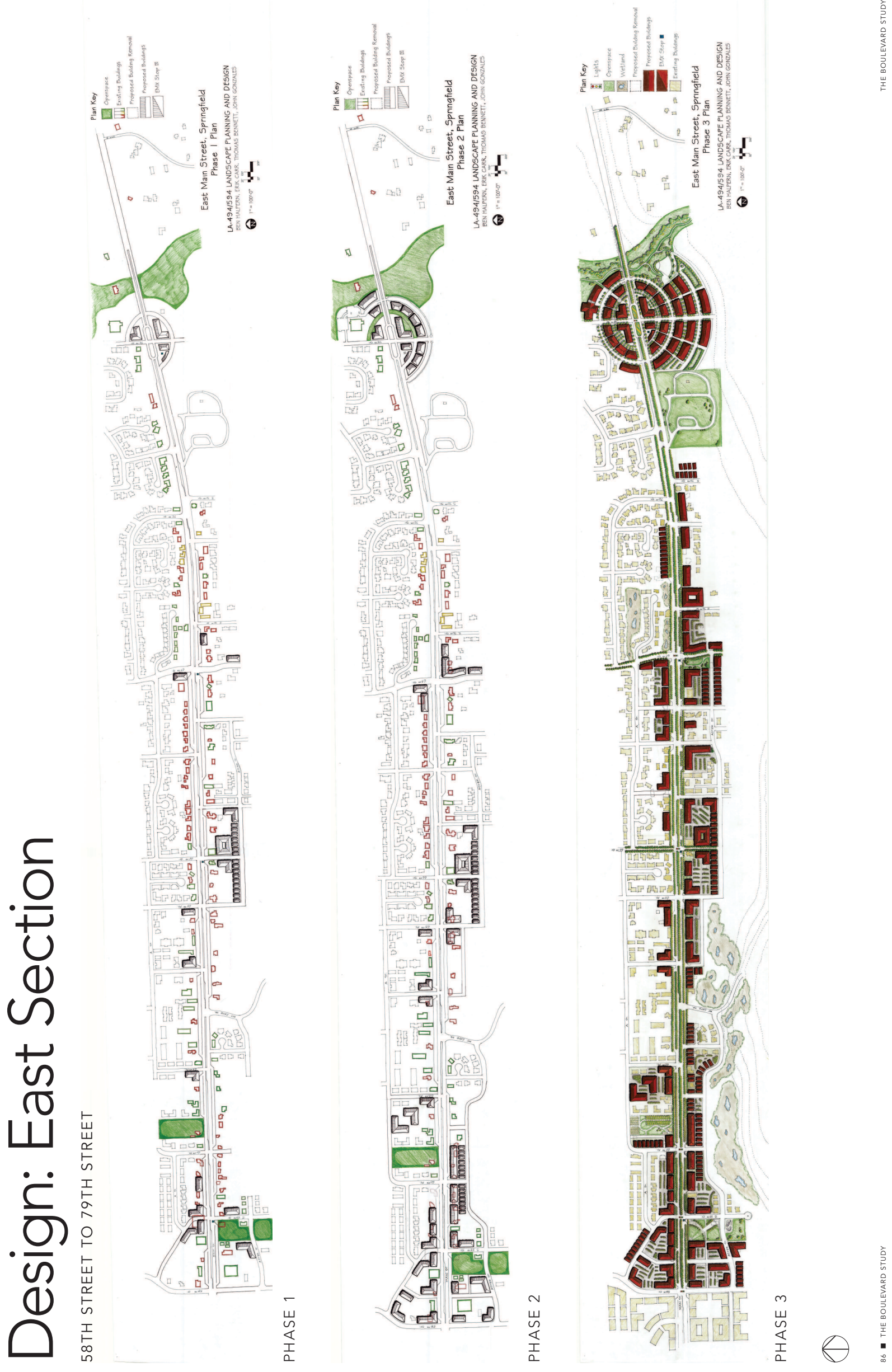

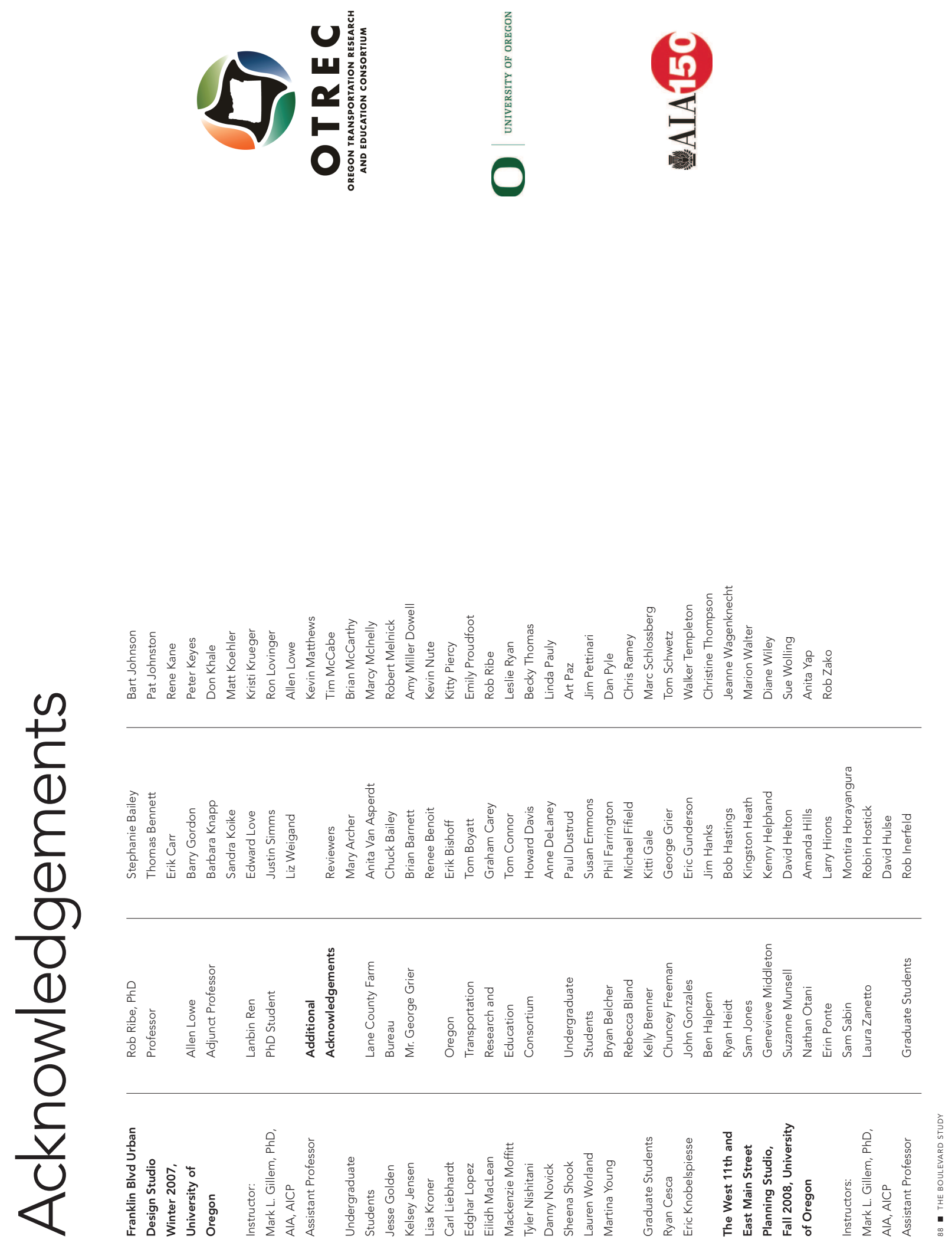


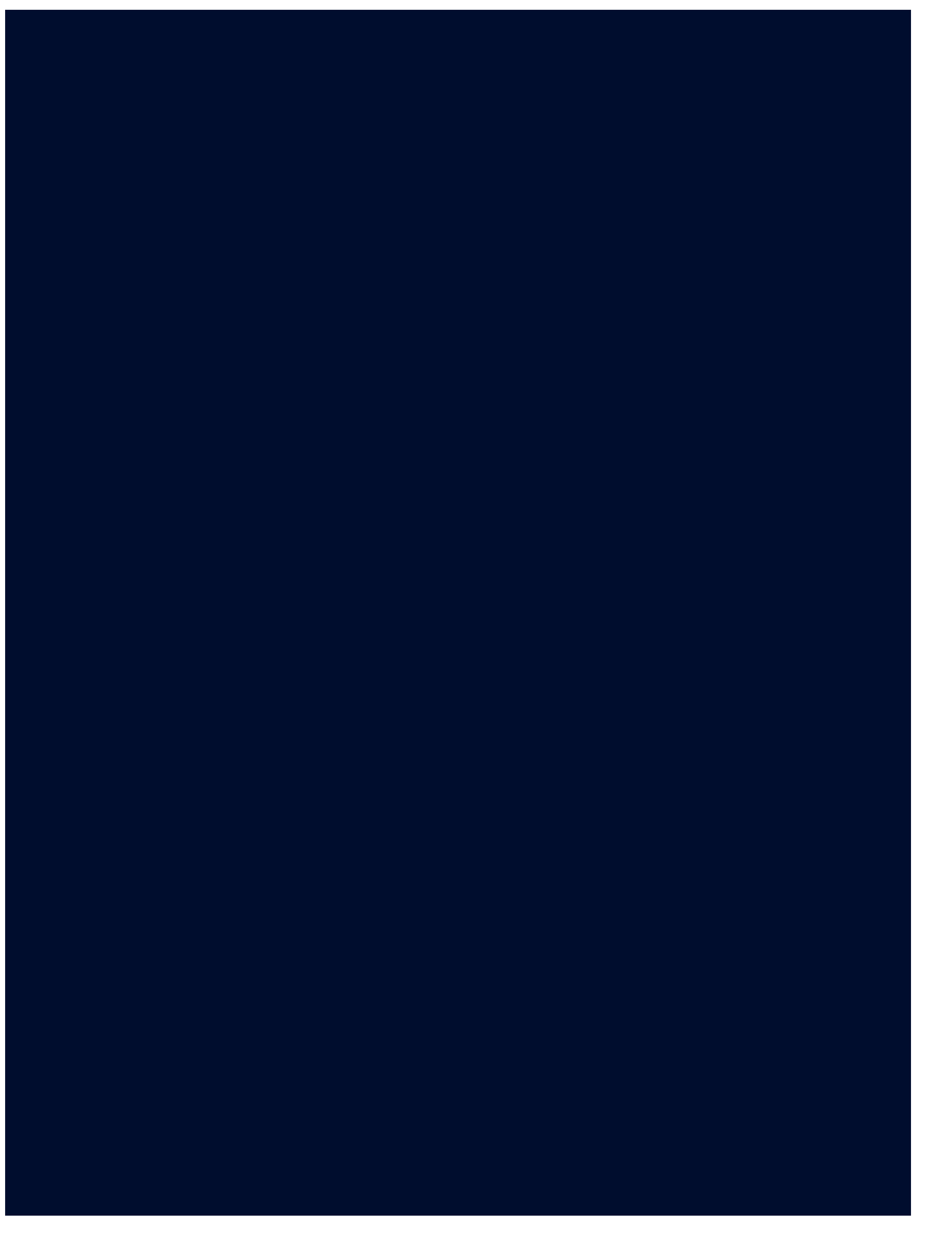




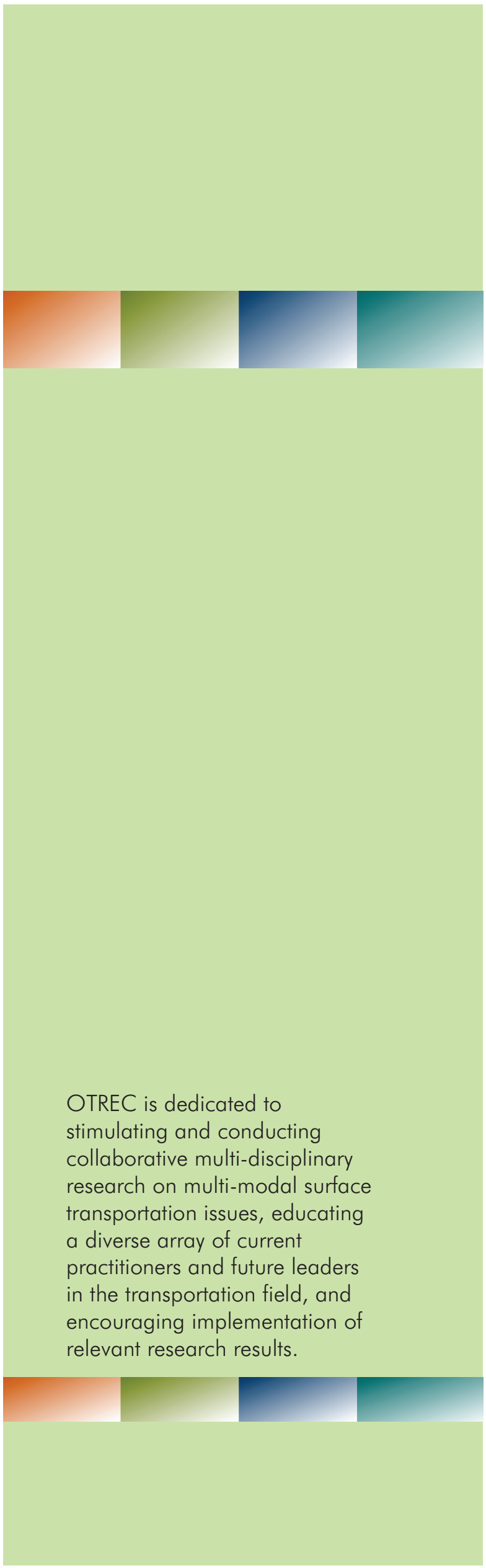

P.O. Box 751

Portland, OR 97207 